\title{
¿Using Satellite Observations to Evaluate the Relationships between Ice Condensate, Latent Heat Release, and Tropical Cyclone Intensification in a Mesoscale Model $^{\mathscr{O}}$
}

\author{
Shun-Nan Wu, ${ }^{a}$ Brian J. Soden,,${ }^{a}$ Yoshiaki Miyamoto,${ }^{\mathrm{a}, \mathrm{c}}$ David S. Nolan, ${ }^{\mathrm{a}}$ AND Stefan A. BuehleR ${ }^{\mathrm{b}}$ \\ ${ }^{a}$ Rosenstiel School of Marine and Atmospheric Science, University of Miami, Miami, Florida \\ ${ }^{\mathrm{b}}$ Meteorologisches Institut, Universität Hamburg, Hamburg, Germany
}

(Manuscript received 18 October 2019, in final form 5 October 2020)

\begin{abstract}
This study examines the relationship between frozen hydrometeors and latent heating in model simulations and evaluates the capability of the Weather Research and Forecasting (WRF) Model to reproduce the observed frozen hydrometeors and their relationship to tropical cyclone (TC) intensification. Previous modeling studies have emphasized the importance of both the amount and location of latent heating in modulating the evolution of TC intensity. However, the lack of observations limits a full understanding of its importance in the real atmosphere. Idealized simulations using WRF indicate that latent heating is strongly correlated to the amount of ice water content, suggesting that ice water content can serve as an observable proxy for latent heat release in the mid- to upper troposphere. Based on this result, satellite observations are used to create storm-centered composites of ice water path as a function of TC intensity. The model reasonably captures the vertical and horizontal distribution of ice water content and its dependence upon TC intensity, with differences typically less than $20 \%$. The model also captures the signature of increased ice water content for intensifying TCs, suggesting that observations of ice water content provide a useful diagnostic for understanding and evaluating model simulations of TC intensification.
\end{abstract}

KEYWORDS: Hurricanes/typhoons; Tropical cyclones; Satellite observations; Model evaluation/performance

\section{Introduction}

Improving the prediction of tropical cyclone (TC) intensity is a priority for operational TC forecasting. The evolution of TC intensity is modulated by both environmental effects and internal dynamics. The environmental effects include vertical wind shear, sea surface temperature, and ambient water vapor (DeMaria and Kaplan 1994; Kaplan and DeMaria 2003; Emanuel et al. 2004; Kaplan et al. 2010), while internal processes include barotropic instability and eyewall dynamics (Montgomery and Kallenbach 1997; Schubert et al. 1999; Hendricks et al. 2010; Wu et al. 2015). Several of these studies have discussed how both processes influence the amount of latent heat release in a storm, which is recognized as the fundamental source of energy that drives TC intensification.

Both the amount and location of latent heat release are important in determining current and future TC intensity. Previous theoretical studies have suggested that the same amount of latent heat release at different locations can have very different impacts on TC intensification (Schubert and Hack 1982; Hack and Schubert 1986). Using a linearized

¿ Denotes content that is immediately available upon publication as open access.

Supplemental information related to this paper is available at the Journals Online website: https://doi.org/10.1175/MWR-D-19-0348.s1.

\footnotetext{
${ }^{\mathrm{c}}$ Current affiliation: Faculty of Environment and Information Studies, Keio University, Kanagawa, Japan.
}

Corresponding author: Shun-Nan Wu, sxw594@rsmas.miami.edu dynamical model, Nolan et al. (2007) demonstrated that the efficiency of energy transformation, from heat energy to kinetic energy, varies depending on the distance of the heating to the TC center and the height of the warm core; When the energy source is close to the TC center or the warm core's height, the efficiency will be higher. Accordingly, measurements of latent heat release are of great value to the prediction of TC intensity. However, there are no observations that can directly measure latent heat release in TCs (Cecil and Zipser 1999; Nolan et al. 2019).

Latent heat release and condensates are generated simultaneously in the upward branch of a convective system, so the release of latent heating is directly proportional to the production of condensate (Yanai et al. 1973). Furthermore, Nolan et al. (2019) found that latent heating is also highly correlated with the amount of condensate, because in order to maintain high values, it must also be continuously produced to replace loss from precipitation. Satellite measurements of radar reflectivity and microwave brightness temperatures provide useful proxies for the amount of liquid and frozen hydrometeors. Previous studies used radar-based retrievals to show the relationship of intense rainfall with rapidly intensifying TCs, and found that TCs with greater areal extent of reflectivity exceeding $20 \mathrm{~dB} Z$ tend to intensify in the future (Zagrodnik and Jiang 2014; Tao and Jiang 2015). Furthermore, several studies have used microwave brightness temperatures to investigate their relationships with TC intensity and intensity change (Cecil and Zipser 1999; Harnos and Nesbitt 2016; Fischer et al. 2018). Harnos and Nesbitt (2016) used 37 and $85 \mathrm{GHz}$ microwave measurements to demonstrate that deep

Publisher's Note: This article was revised on 5 March 2021 to designate it as open access. 
convective clouds are more vigorous in rapidly intensifying TCs than in nonintensifying TCs in higher shear environment, although no clear differences were found between TCs that underwent slow and rapid intensification. Fischer et al. (2018) developed a method, using normalized brightness temperatures, to predict rapid intensification events, showing the potential of satellite measurements to forecast future TC intensity. Other studies examined satellite-measured brightness temperature and observed environmental factors, utilizing their relationships with future changes in TC intensity, to improve statistical models for forecasting future TC intensity (DeMaria et al. 2005). However, the inability to measure the vertical distribution of hydrometeors is a crucial factor that limits the effectiveness of such models. In addition, such observations are also necessary for the validation of dynamical model simulations.

The CloudSat cloud profiling radar provides vertically resolved measurements of hydrometeors, cloud ice, and liquid water, which can serve as a reference to validate model simulations (Austin et al. 2009; Tourville et al. 2015). A recent study by Wu and Soden (2017) used CloudSat-measured ice water content (IWC) to establish its relationship with future changes in TC intensity. They demonstrated that TCs with greater IWC throughout the entire ordinate of composites tend to intensify in the subsequent $24 \mathrm{~h}$. Though the narrow swath of CloudSat overpasses limits the spatial and temporal coverage of TCs, these high-resolution measurements have a potential to benefit the prediction of future TC intensity.

Numerical models can simulate the evolution of TCs, generating output over a large and continuous space-time domain. Miyamoto and Nolan (2018) used the Weather and Research Forecasting (WRF) Model to generate $270 \mathrm{TC}$ simulations and investigate the relationship between the rates of TC intensification and both internal and environmental conditions. Using similar model configurations, a recent study showed that volume-integrated latent heating is closely correlated with volume-integrated condensates in TCs (Nolan et al. 2019). However, how well latent heating relates to frozen hydrometeor concentration, especially where the energy transformation efficiency for TCs is higher, has not been specifically addressed.

In this study, we use the same ensemble simulations from Miyamoto and Nolan (2018) to examine how well the evolution of simulated latent heating relates to the concentration of frozen hydrometeors and how well WRF reproduces frozen hydrometeors seen in the observations. Because this ensemble of simulations only uses one microphysics scheme (a 6-class single-moment scheme), we also develop another set of simulations that adopts a different microphysics scheme in order to account for the influence of microphysics schemes on the production of cloud ice (McFarquhar et al. 2006; Jin et al. 2014). Understanding their relationships can be used to better interpret satellite measurements of frozen hydrometeors. Using two satellite datasets, CloudSat and the passive microwave SPARE-ICE retrievals of IWP, we examine the performance of the WRF Model in simulating both the vertical and horizontal distributions of frozen hydrometeors and the relationships between frozen hydrometeor concentrations and TC intensification. Such an evaluation can help constrain the simulated frozen hydrometeors
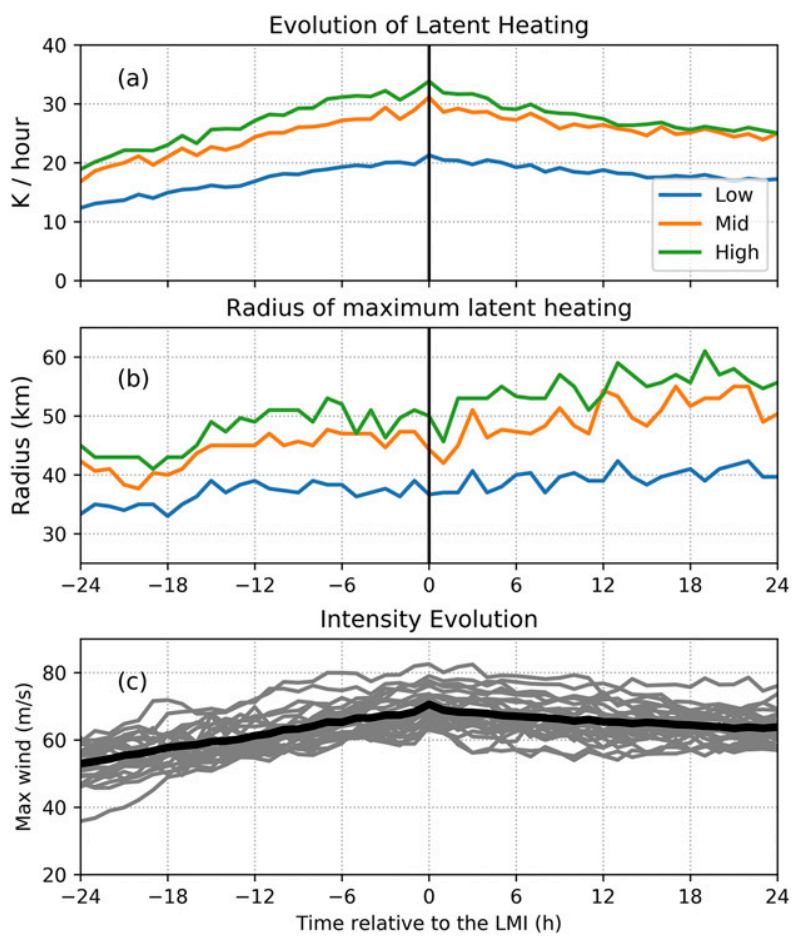

FIG. 1. The evolution of (a) areal mean latent heat release within $10 \mathrm{~km}$ of the radius of the maximum latent heating $\left(\mathrm{K} \mathrm{h}^{-1}\right)$ and (b) averaged radius of the radius of top $10 \%$ latent heat release $(\mathrm{km})$. Blue, orange, and green solid lines represent low, mid-, and upper levels, respectively. (c) The evolution of TC intensity from the WRF simulations.

in models and understand to what extent frozen hydrometeors can be related to future changes in TC intensity.

\section{Methods and data}

This study uses three different datasets: 1) 10 years of CloudSat measurements of ice water content; 2) 5 years of passive microwave retrievals of vertically integrated ice water content from SPARE-ICE; and 3) output from an ensemble of WRF simulations of idealized TCs.

\section{a. CloudSat}

CloudSat is equipped with a cloud profiling radar that retrieves vertically resolved cloud ice and liquid water condensates, with horizontal resolution of $1.1 \mathrm{~km}$ and vertical resolution of $0.24 \mathrm{~km}$. The CloudSat Tropical Cyclone Dataset contains more than 10000 CloudSat overpasses that are within $1000 \mathrm{~km}$ of the TC center and spans the years 2006-17 on a global scale (Tourville et al. 2015). Since CloudSat does not necessarily penetrate through the TC center, we define the point of closest approach (PCA) as the position on overpasses with the closest distance to the TC center. To focus on the TC core, we select only those overpasses whose distance from the PCA to the TC center is less than $300 \mathrm{~km}$. Although this criterion is larger than the typical size of a TC inner core, it is used to obtain a sufficient sample size. This selection criterion yields $\sim 1500$ 

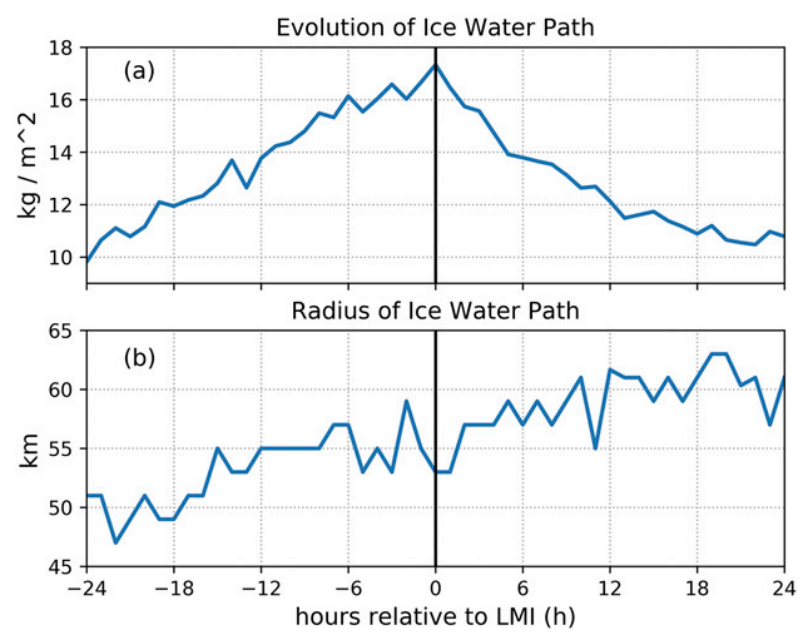

FIG. 2. The evolution of (a) areal mean IWP within $10 \mathrm{~km}$ of the maximum IWP $\left(\mathrm{kg} \mathrm{m}^{-2}\right)$ and (b) averaged radius of the top $10 \%$ IWP $(\mathrm{km})$ from the WRF simulations.

CloudSat overpasses. Both intensifying and weakening TCs have approximately 500 overpasses each. For additional details regarding the CSTC dataset and the selection criteria of CloudSat overpasses, please refer to Tourville et al. (2015) and Wu and Soden (2017).

\section{b. SPARE-ICE}

Holl et al. (2014) describes the SPARE-ICE dataset that contains 5 years of ice water path (IWP) retrievals (vertically integrated frozen hydrometeors). The data span 2006 to 2010 with global coverage and have a footprint size of $16 \mathrm{~km}$ near the swath center, degrading to $52 \mathrm{~km} \times 27 \mathrm{~km}$ at the swath edge. IWP is retrieved using a combination of terrestrial infrared and microwave data from passive sensors mounted on satellites, together with an artificial neural network trained with IWP from CloudSat measurements. Infrared channels are from the Advanced Very High Resolution Radiometer (AVHRR), and microwave measurements of frequencies from 89 to $190 \mathrm{GHz}$ are from the Advanced Microwave Sounding Unit-B (AMSU-B) as well as the Microwave Humidity Sounder (MHS) carried on NOAA satellites. SPARE-ICE only uses channels near the $183 \mathrm{GHz}$ water vapor absorption frequency at $183 \pm 1, \pm 3$, and $\pm 7 \mathrm{GHz}$ (AMSU-B) or $190 \mathrm{GHz}$ (MHS) to minimize impacts of surface emissivity variations on the IWP. An artificial neural network was trained based on CloudSat product 2 C-ICE (Deng et al. 2010), so this dataset inherits all systematic errors and limitations in $2 \mathrm{C}$-ICE products. One limitation of CloudSat measurements is the radar beam's attenuation under heavy rainfall conditions. Complete details related to SPARE-ICE products are available from Holl et al. (2014).

To use the SPARE-ICE product for TC research, we use the International Best Track Archive for Climate Stewardship
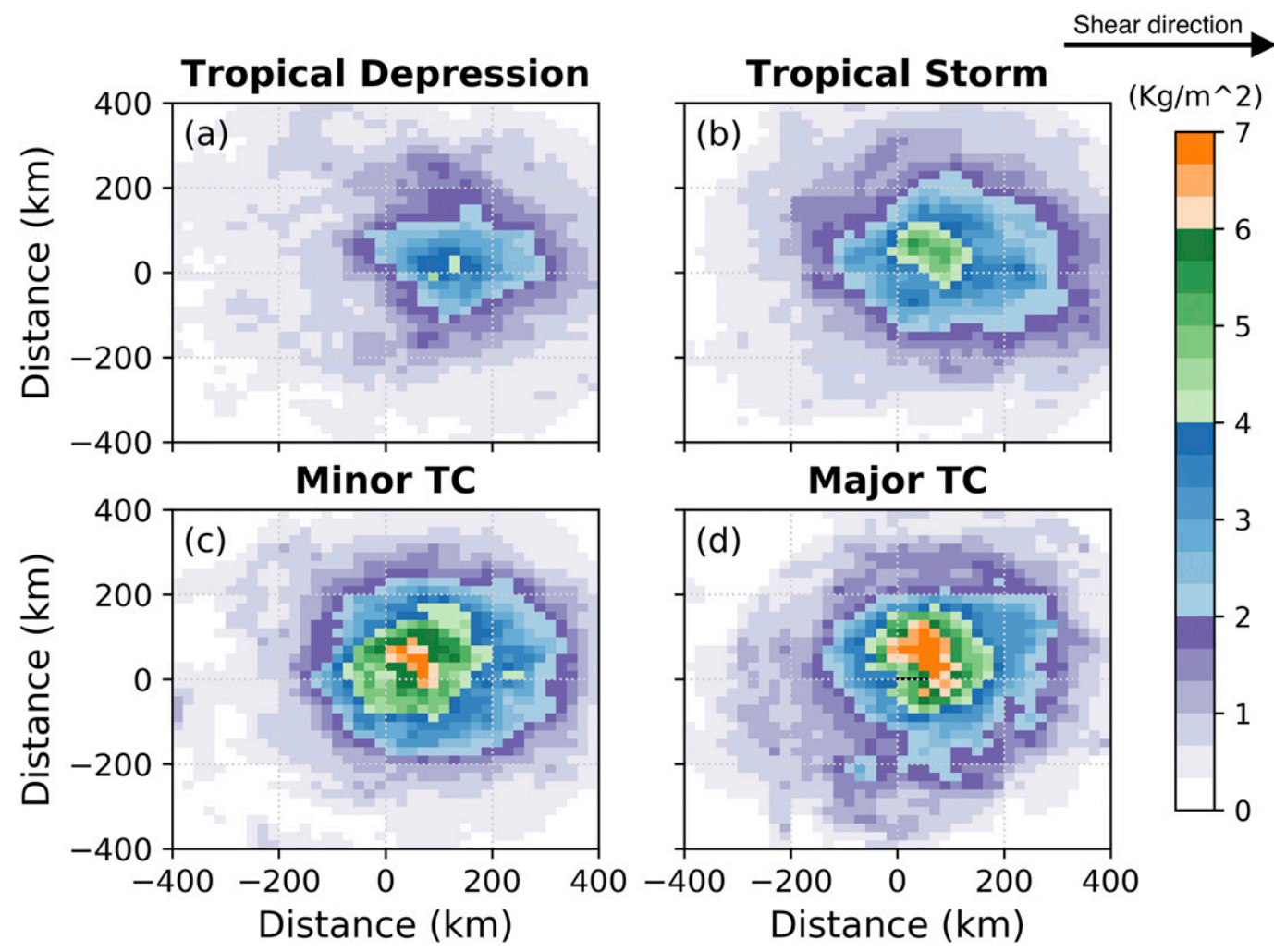

FIG. 3. Composites of IWP (shading; $\mathrm{kg} \mathrm{m}^{-2}$ ) from SPARE-ICE for (a) TDs, (b) TSs, (c) minor TCs, and (d) major TCs. The $x$ and $y$ axis are the distance from the TC center in $\mathrm{km}$. The direction of the vertical wind shear is toward the right of the figure. 


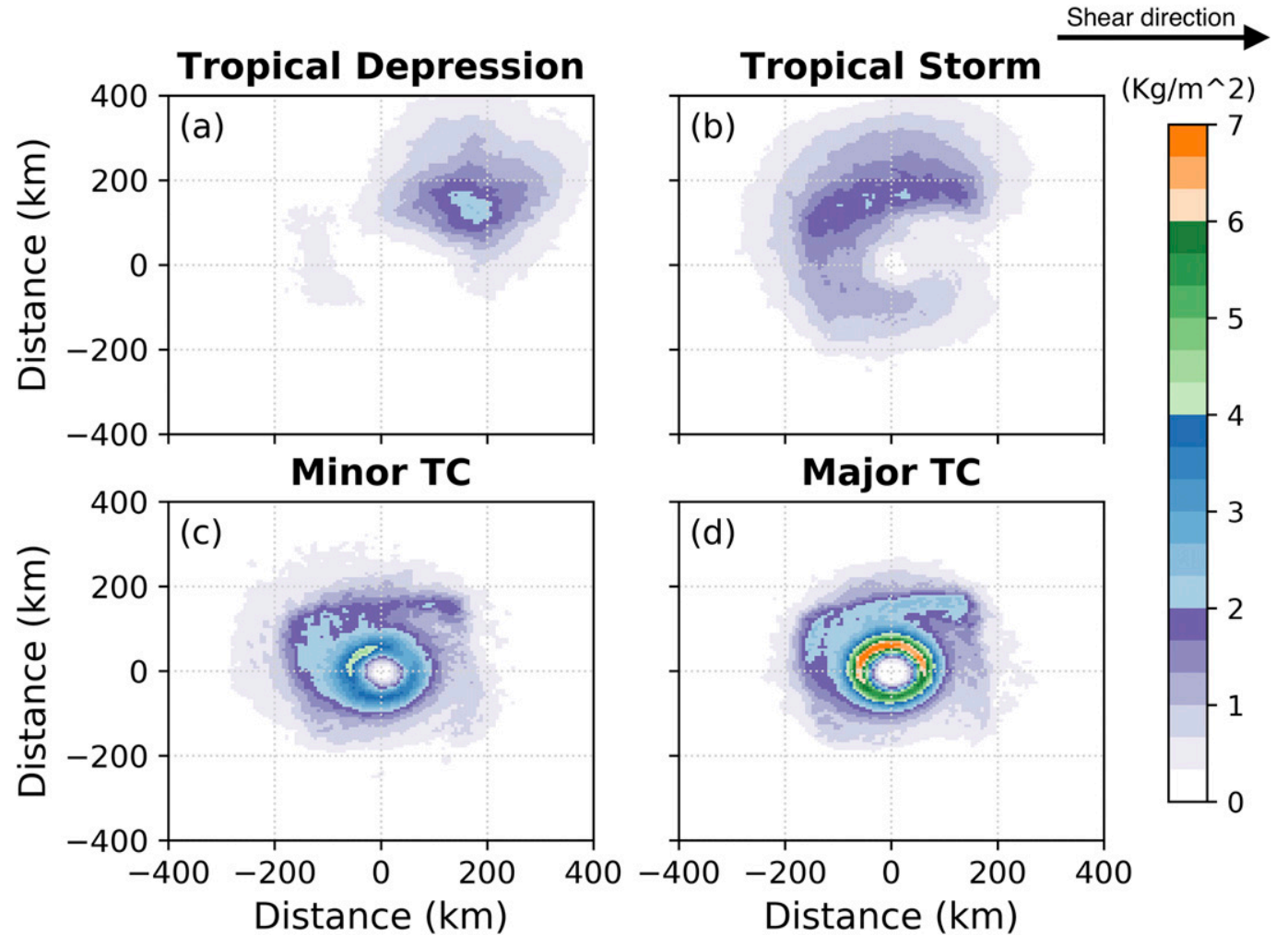

FIG. 4. As in Fig. 3, but from the WRF simulations.

(IBTrACS; Knapp et al. 2010) to identify the location and intensity of storms with 6-h time intervals. Since the time of SPARE-ICE retrievals is asynoptic, the TC associated information at the satellite time is determined by linearly interpolating the IBTrACS data. Two criteria are applied to select TCs in the SPARE-ICE: 1) The distance from maximum IWP to the TC center has to be less than $100 \mathrm{~km}, 2$ ) IWP has to be greater than 0 over at least half of the area. For the 5-yr period considered here, there are 544 snapshots of TCs identified in SPARE-ICE and adopted in this study. Furthermore, as vertical wind shear is one of the major causes responsible for TC asymmetry (Corbosiero and Molinari 2003), we use the NASA MERRA2 data to derive the direction of vertical wind shear, and then rotate TCs to the same direction of vertical wind shear. The vertical wind shear is calculated by averaging the wind fields between 200 and $800 \mathrm{~km}$ of the TC center and then subtracting wind fields between 300 and $700 \mathrm{hPa}$. The magnitude of wind shear exhibits a nearly Gaussian distribution with a mean of $\sim 6 \mathrm{~m} \mathrm{~s}^{-1}$, and $\sim 5 \%$ of the cases whose magnitude is greater than $14 \mathrm{~m} \mathrm{~s}^{-1}$.

For CloudSat and SPARE-ICE datasets, the change in TC intensity is determined using the 6 -h difference in maximum wind speed between the reported time and that $6 \mathrm{~h}$ later. If the maximum wind speed increases $2.57 \mathrm{~m} \mathrm{~s}^{-1}(5 \mathrm{kt})$ or more, the storm is defined as intensifying, while if the wind speed decreases more than $2.57 \mathrm{~m} \mathrm{~s}^{-1}$, the storm is defined as weakening. All others are categorized as neutral. We further separate the dataset into four intensity categories based on TC intensity at the reported time: tropical depression (TD; $<18 \mathrm{~m} \mathrm{~s}^{-1}$ ), tropical storm (TS; $\left.18-33 \mathrm{~m} \mathrm{~s}^{-1}\right)$, minor TC $\left(33-50 \mathrm{~m} \mathrm{~s}^{-1}\right)$, and major TC $\left(>50 \mathrm{~m} \mathrm{~s}^{-1}\right)$, to minimize the influence of TC intensity on the comparison of variables.

\section{c. WRF simulations}

Miyamoto and Nolan (2018) used WRF, version 3.7, with an idealized configuration to perform a series of 7-day simulations. They created 270 ensemble members by changing the vertical wind shear ( 0 to $12.5 \mathrm{~m} \mathrm{~s}^{-1}$ with the interval of $2.5 \mathrm{~m} \mathrm{~s}^{-1}$ ), translation speed ( 2.5 to $12.5 \mathrm{~m} \mathrm{~s}^{-1}$ with the interval of $\left.2.5 \mathrm{~m} \mathrm{~s}^{-1}\right)$, initial TC intensity $\left(10,15,20 \mathrm{~m} \mathrm{~s}^{-1}\right)$, and the initial size $(90,150,210 \mathrm{~km})$. The horizontal resolution of the innermost domain for these simulations is $2 \mathrm{~km}$ with 40 vertical layers. The point downscaling method in Nolan (2011) is used to create spatially and temporally homogenous background wind throughout the entire simulations. The microphysical parameterization adopted is the 6-class single-moment scheme known as WSM6 (Hong and Lim 2006). Because microphysics schemes strongly regulate the amount of cloud ice and liquid, we create another small ensemble with 5 members using a different microphysics parameterization - the Thompson scheme (Thompson et al. 2004). The small ensemble has the same configuration as the large ensemble simulations, except initial vortex intensity. The initial vortex intensity in the small ensemble all start from $5 \mathrm{~m} \mathrm{~s}^{-1}$, whereas the initial vortex intensity of the large ensemble ranges from 10 to $20 \mathrm{~m} \mathrm{~s}^{-1}$. Different magnitudes of wind shear are used to create 5 members $\left(2.5\right.$ to $12.5 \mathrm{~m} \mathrm{~s}^{-1}$, with an interval of 

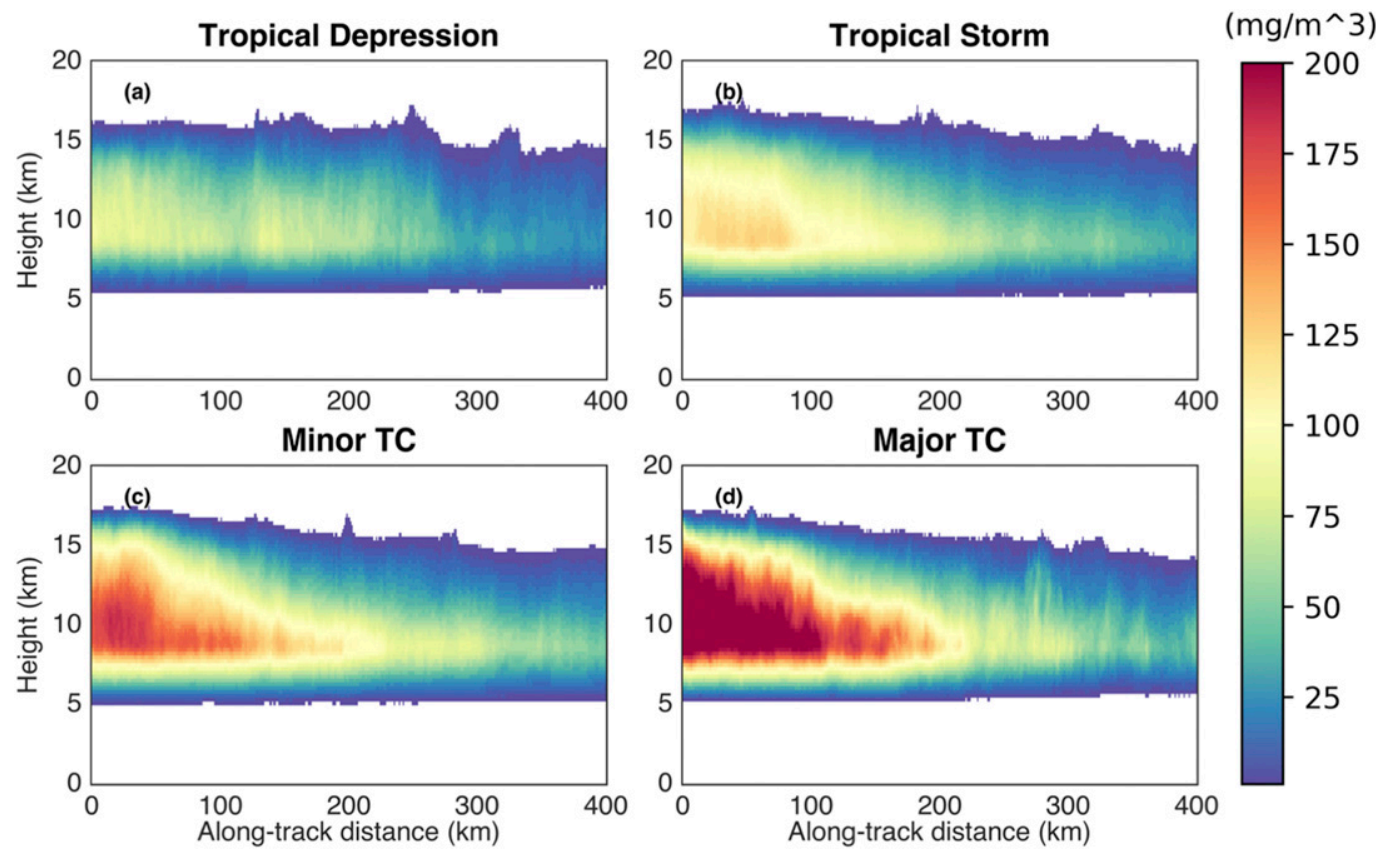

FIG. 5. Composites of IWC (shading; $\mathrm{mg} \mathrm{m}^{-3}$ ) from CloudSat measurements for (a) TDs, (b) TSs, (c) minor TCs, and (d) major TCs. The $x$ axis is the axial distance from the PCA in $\mathrm{km}$ and the $y$ axis is height in $\mathrm{km}$.

$2.5 \mathrm{~m} \mathrm{~s}^{-1}$ ). The small ensemble has a similar distribution of TC intensity as the large ensemble simulations.

Two averaging methods are used to sample the WRF simulations: 1) an azimuthal average and 2) a CloudSat-footprintlike slicing method. We axisymmetrize the variables related to latent heating and frozen hydrometeors to examine their relationships, since the axisymmetrization better presents TC dynamics in a simpler and intuitive way. To evaluate the ability of the WRF Model to reproduce the CloudSat-measured frozen hydrometeors, we develop a CloudSat-footprint-like slicing method, subsampling the model data by selecting crosssections from 0 to $300 \mathrm{~km}$ with the interval of $30 \mathrm{~km}$ from the storm center to mimic the way CloudSat measures TCs. The cross-sections are parallel to the $x$ and $y$ axes with 21 crosssections in each direction. For both methods, any 6-h window within simulation time are all separate composites to avoid oversampling (e.g., 0-6, 6-12, 12-18 h).

The TC intensity in the WRF simulations is defined as the maximum azimuthal mean tangential wind at the height of $2 \mathrm{~km}$, because the tangential wind at this height often evolves much more smoothly than that within the boundary layer in model simulations. We note that this definition is different from IBTrACS that uses $10 \mathrm{~m}$ wind speed. The change in TC intensity is calculated from the difference between TC intensity at the simulated time and $6 \mathrm{~h}$ later. If the intensity grows stronger or weaker by more than $3 \mathrm{~ms}^{-1}$ in $6 \mathrm{~h}$, we define it as intensifying or weakening. Within each intensity category, there are more intensifying TCs than weakening TCs, except in the TD category (see Fig. S1 in the online supplemental material). It is noted that although intensifying TDs for the 6-h lead time has a lower sample size (16 cases), they demonstrate a behavior consistent with other intensity categories. We also isolate the 48 -h period, $24 \mathrm{~h}$ prior to and after the time of the TC's lifetime maximum intensity (LMI), to examine how the evolution of latent heating relates to that of frozen hydrometeors. It is noted that the period from $24 \mathrm{~h}$ before to the LMI is usually an intensifying period, whereas the period from the LMI to $24 \mathrm{~h}$ after is a weakening period.

\section{d. Measuring and simulating frozen hydrometeors}

It is known that frozen hydrometeors are mostly composed of ice, snow, and graupel. The CloudSat categorizes all species of frozen hydrometeors as IWC. Previous studies have applied various methods of separating the observed IWC into nonprecipitating (ice crystal) and precipitating (snow and graupel) frozen hydrometeors (Waliser et al. 2009; Chen et al. 2011; Deng et al. 2018). Waliser et al. (2009) uses a precipitating condition based on measurements from CloudSat and CALIPSO to distinguish two types of frozen hydrometeors, while the other studies utilize particle size to separate different types of frozen hydrometeors. In this study, we adopt the method of Waliser et al. (2009) to distinguish between precipitating and nonprecipitating frozen hydrometeors to validate model's ability to replicate nonprecipitating frozen hydrometeors.

In the WRF Model, two microphysics schemes used in this study separate frozen hydrometeors into three species: ice, snow and graupel. Therefore, we add up ice, snow, and graupel from the WRF Model so that we can quantitatively compare the simulated frozen hydrometeors to the CloudSat-measured frozen hydrometeors. In the following analysis, the ordinates for the SPARE-ICE and WRF idealized simulations is shown using the radius to the TC center, whereas the ordinate for CloudSat measurements is the distance from the PCA, unless otherwise specified. 

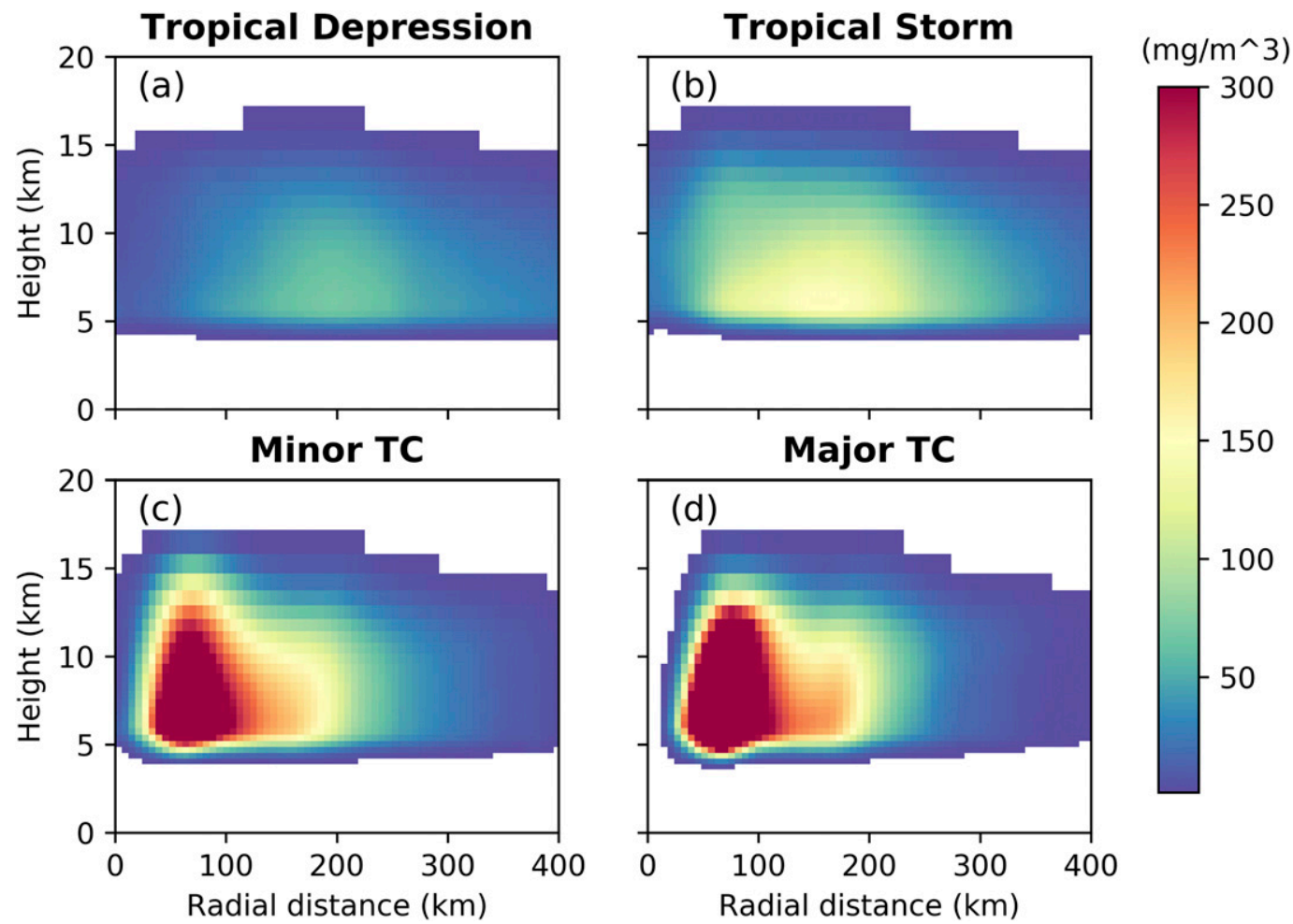

FIG. 6. Composites of IWC (shading; $\mathrm{mg} \mathrm{m}^{-3}$ ) from the WRF simulations for (a) TDs, (b) TSs, (c) minor TCs, and (d) major TCs. The $x$ axis is the radius in $\mathrm{km}$ and the $y$ axis is height in $\mathrm{km}$.

\section{Relationship between latent heating and frozen hydrometeors}

We use WRF simulations to examine how latent heating at different heights is related to frozen hydrometeor concentration. The amounts of latent heat release and frozen hydrometeors are strongly associated with current TC intensity. Thus, we examine the evolution of TC intensity in the 24-h periods prior to and after the LMI. Only those storms with LMI exceeding $30 \mathrm{~m} \mathrm{~s}^{-1}$ are considered. As an average, the TC intensity grows by $\sim 10 \mathrm{~m} \mathrm{~s}^{-1}$ in the $24 \mathrm{~h}$ prior to the LMI (intensifying period). After the LMI, the intensity weakens at a slower rate of $\sim 5 \mathrm{~m} \mathrm{~s}^{-1}$ in $24 \mathrm{~h}$ (weakening period). The average TC intensity is weaker during the intensifying period than during the weakening period (Fig. 1).

To investigate how latent heating evolves prior to and after the LMI, we calculate vertically averaged latent heating $24 \mathrm{~h}$ prior to and after the LMI for three levels: low level is $0-3 \mathrm{~km}$ ( $\sim$ surfacen $700 \mathrm{hPa})$, midlevel is $3-6 \mathrm{~km}(\sim 700-500 \mathrm{hPa})$, and upper level is $6-9.5 \mathrm{~km}(\sim 500-300 \mathrm{hPa})$. In all three levels, the time of maximum latent heating coincides with the time of the LMI, so the amount of latent heating is smaller both before and after the LMI (see Fig. S2).

Figure 1 shows the evolution of the mean latent heat release within $10 \mathrm{~km}$ of the radius of maximum latent heating (Fig. 1a), and the average radius of the top $10 \%$ latent heat release (Fig. 1b) for all three levels. Latent heating in all three levels increases with time before the LMI and then decreases after the LMI. This evolution is consistent with the previous study that showed a high correlation coefficient of approximately 0.9 between latent heating and current TC intensity (Nolan et al. 2019). The averaged radius in all three levels generally increases with time, while it behaves differently $12 \mathrm{~h}$ prior to and after the LMI for the three levels. In the low level, the evolution of latent heating mirrors the intensity, increasing steadily before the LMI $\left(\sim 2 \mathrm{~K} \mathrm{~h}^{-1}\right.$ in $\left.6 \mathrm{~h}\right)$ and gradually decreasing after the LMI $\left(\sim 2 \mathrm{~K} \mathrm{~h}^{-1}\right.$ in $\left.6 \mathrm{~h}\right)$, with the radius of maximum latent heating remaining constant $12 \mathrm{~h}$ prior to and after the LMI. In the midlevels, the amount of maximum latent heating evolves similarly to that at the low levels (increasing $\sim 3.9 \mathrm{~K} \mathrm{~h}^{-1}$ in $6 \mathrm{~h}$ and decreasing $\sim 3.8 \mathrm{~K} \mathrm{~h}^{-1}$ in $6 \mathrm{~h}$ ), yet its radius moves slightly outward with time ( $\sim 9 \mathrm{~km}$ in 24 -h period). For the upper-level, the radius of maximum latent heating also shifts slightly outward with time ( $\sim 5 \mathrm{~km}$ in 24 -h period). However, unlike the low and midlevels whose evolving rates of latent heating are mirrored by the LMI, the upper-level latent heating declines more rapidly after passing the LMI (increasing $\sim 2.6 \mathrm{~K} \mathrm{~h}^{-1}$ in $6 \mathrm{~h}$ and decreasing $\sim 4.7 \mathrm{~K} \mathrm{~h}^{-1}$ in $6 \mathrm{~h}$ ). Though the results above are simply based on the averaged evolution of latent heating, the spread of the ensembles is consistently small throughout this period; the standard errors are only about $2 \%$ of the ensemble mean for each level $\left(0.66,1.12\right.$, and $0.99 \mathrm{~K} \mathrm{~h}^{-1}$ for the low, mid-, and upper levels, respectively). The small standard errors support the argument that the upper level is the only level that has substantially reduced latent heating after the LMI.

We repeat the same analysis for IWP to examine its relationship with latent heating. Figure 2 a shows that the amount 

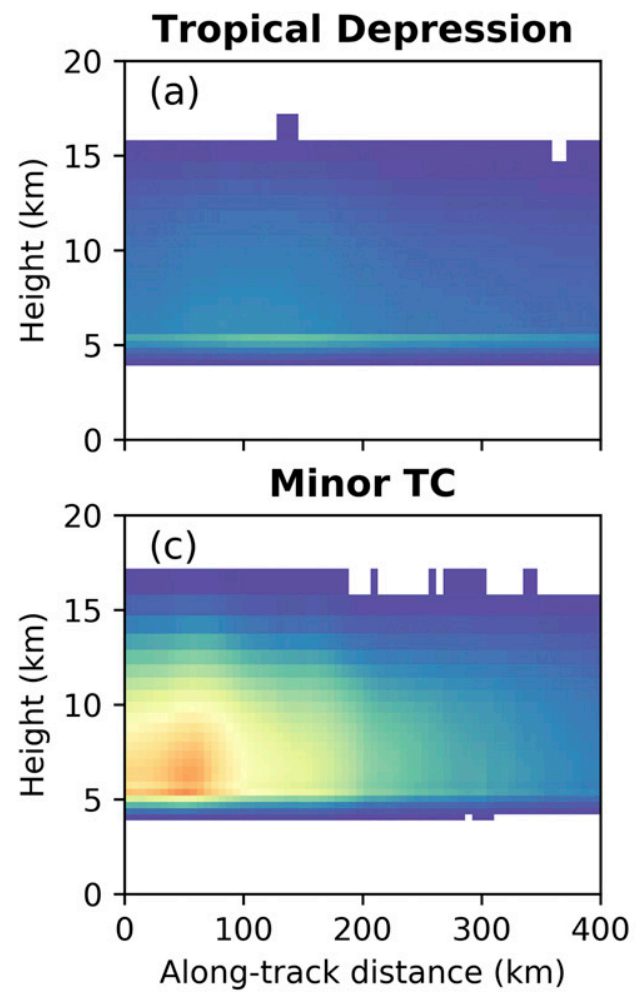

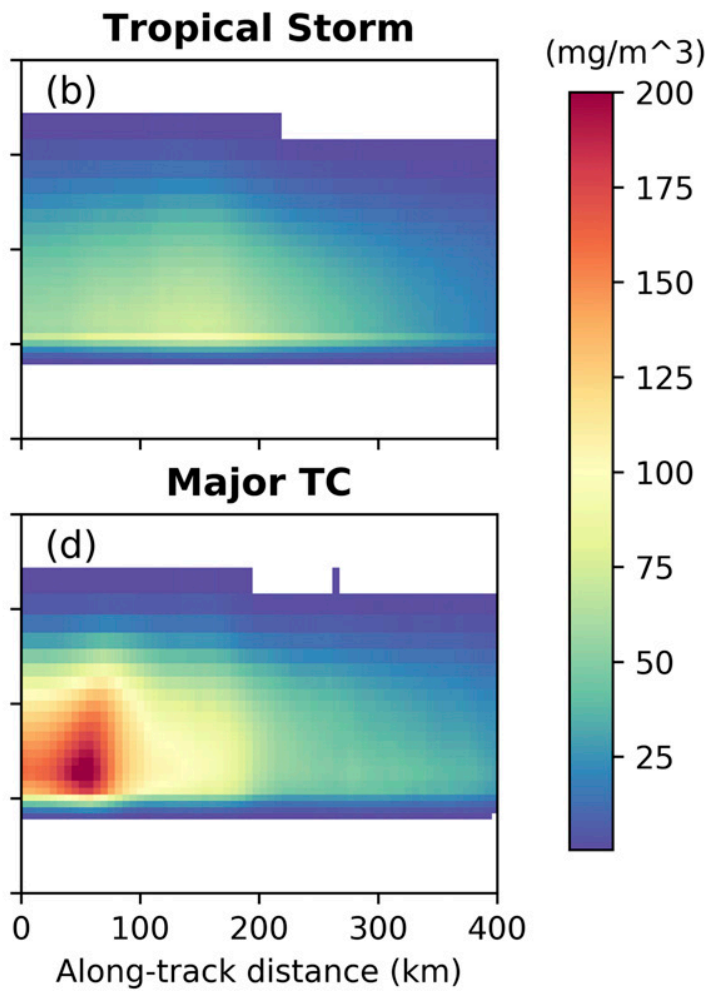

FIG. 7. As in Fig. 5, but from the WRF simulations.

of maximum IWP increases steadily prior to the time of LMI $\left(1.9 \mathrm{~kg} \mathrm{~m}^{-2}\right.$ in $\left.8 \mathrm{~h}\right)$, while it drops sharply after the LMI $\left(3.8 \mathrm{~kg} \mathrm{~m}^{-2}\right.$ in $8 \mathrm{~h}$ ). The radius of maximum latent heating also expands outward with time during this period (Fig. 2b). The correlation coefficients between IWP and upper-level latent heating are 0.98 and the correlation between their radii is 0.94 . For low and midlevels, the coefficients are 0.9 for the amounts and below 0.89 for the radii. We speculate that the increase in radius before the LMI may be due to the tilt of the eyewall associated with the secondary circulation. After the LMI, it may be caused by the expansion of eyewall related to the weakening of TCs. Such evolving patterns of IWP are nearly identical to that of latent heating in the upper-level, indicating that, for this model, IWP provides an accurate proxy of upper-level latent heating. Additionally, it is noted that only the upper-level latent heating evolves differently from that of TC intensity, indicating upper-level latent heating might have information about future TC intensity, rather than current intensity.

\section{Evaluation of simulations by comparison to observations}

In this section, we utilize the relationship between latent heating and frozen hydrometeor concentration to evaluate the model's ability to simulate the distribution of latent heating and its dependence on TC intensity.

\section{a. Horizontal distribution of IWP}

We use retrievals from the SPARE-ICE dataset to examine how IWP is distributed horizontally in TCs and to validate the simulated IWP from the WRF Model. Several observational studies have illustrated the importance of shear-relative precipitation distributions to the evolution of TC intensity (Corbosiero and Molinari 2003; Alvey et al. 2015; Fischer et al. 2018). To account for the influence of vertical wind shear on the asymmetric distribution of IWP, the distribution of IWP is rotated to the same direction of vertical wind shear before compositing. Figure 3 shows the composites of horizontal IWP from the SPARE-ICE for four intensity categories, with the direction of vertical wind shear toward the right of the figure. For all intensity categories, IWP is concentrated at the TC center and monotonically decreases outward, though some composites show a ring-like distribution, likely a sign of an eyewall. As TC intensity increases, the IWP within the TC domain increases and the area with IWP greater than $4 \mathrm{~kg} \mathrm{~m}^{-2}$ expands. Interestingly, the distribution of IWP for all intensity categories is asymmetric, especially for TD and TS, with the maximum at the downshear left-quadrant. The asymmetric distribution is consistent with previous studies using the kinematic analysis to demonstrate that the innermost convection is most intense in the downshear-left quadrant (Hence and Houze 2012; Reasor et al. 2013; DeHart et al. 2014).

We perform the same analysis for the WRF simulations (Fig. 4). Compared with the SPARE-ICE, the amount of IWP in the model simulations is $\sim 30 \%$ less in both TD and TS (Figs. $4 \mathrm{a}, \mathrm{b}$ ), whereas it is $\sim 15 \%$ more in the category of major TC (Fig. 4d). The smaller amount of simulated IWP in the TD and TS two categories may be partially related to model spinup, as these intensity categories are usually found in the 

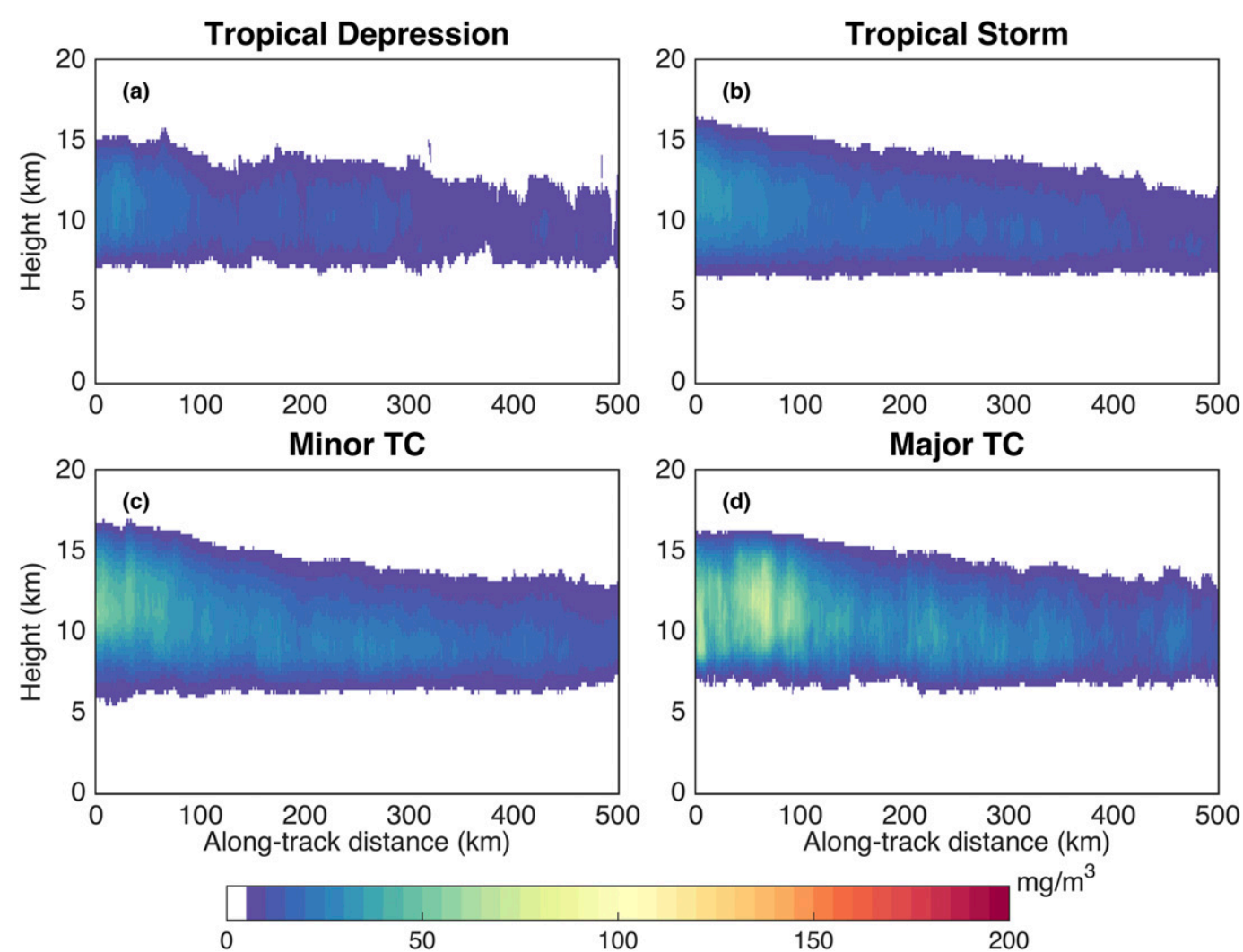

FIG. 8. Composites of nonprecipitating IWC (shading; $\mathrm{mg} \mathrm{m}^{-3}$ ) from CloudSat measurements for (a) TDs, (b) TSs, (c) minor TCs, and (d) major TCs. The $x$ axis is the axial distance from the PCA in $\mathrm{km}$ and the $y$ axis is height in $\mathrm{km}$.

early stage of our simulations. Similar to the SPARE-ICE, the distribution of IWP in the simulations is concentrated at the inner core region, with the maximum at the eyewall for all intensity categories except TD. A distinct asymmetric distribution of IWP also occurs in TD and TS with larger IWP at the left-hand side of the shear direction for all intensity categories, consistent with the SPARE-ICE. The maximum IWP in the model migrates from downshear left to upshear left, as the category of TC intensity strengthens from TD to minor TC, consistent with previous studies (Alvey et al. 2015; Fischer et al. 2018). However, in contrast to the SPARE-ICE composites, the area with high IWP decreases as TC intensity increases. The difference in the areal coverage of IWP may be caused by reduced environmental moistening in the model due to the idealized configuration, which may lead to less production of cloud ice outside the eyewall. In addition, maximum IWP in the model simulations occurs as a ring shape at the eyewall region, while it is concentrated at the TC center in the SPARE-ICE. This difference may be caused by the compositing method applied for the SPARE-ICE or different horizontal resolutions between the SPARE-ICE and the WRF simulations, and will be further discussed later in the paper.

\section{b. Vertical distribution of IWC}

Next, we examine the vertical distribution of IWC from CloudSat measurements. Figure 5 shows the cross-sectional composites of IWC from CloudSat measurements for four intensity categories. IWC is concentrated within $100 \mathrm{~km}$ of the PCA at a height of $5-15 \mathrm{~km}$, with the maximum located near the PCA, and decreases away from the PCA. The maxima IWC are $106 \mathrm{mg} \mathrm{m}^{-3}$ in TD, $141 \mathrm{mg} \mathrm{m}^{-3}$ in TS, $190 \mathrm{mg} \mathrm{m}^{-3}$ in minor TC, and $269 \mathrm{mg} \mathrm{m}^{-3}$ in major TC. The amount of IWC increases with TC intensity, especially within $200 \mathrm{~km}$ of the PCA. The increase of IWC along with TC intensity in CloudSat measurements is consistent with previous studies that displayed a high correlation between TC intensity and the magnitude of cloud ice (Cecil and Zipser 1999; Nolan et al. 2019).

In the WRF Model simulations, azimuthally averaged IWC is concentrated within $200 \mathrm{~km}$ of the TC center at a height of 5$15 \mathrm{~km}$, consistent with the observed IWC. This distribution of IWC is similar to the distribution of simulated condensates in Fovell et al. (2016). The simulated IWC has comparable values with the observed IWC in TD and TS (Figs. 6a,b), whereas the simulated IWC is, on average, up to $30 \%$ greater than observations in the minor and major TC within $200 \mathrm{~km}$ radii (Figs. 6c,d). A distinct difference appears near the region of zero ordinate between the simulated and the observed IWC. That is, the maximum IWC in CloudSat measurements extends inward all the way to zero ordinate, whereas the IWC in model simulations decreases to negligible values within one RMW. The difference between CloudSat and WRF is because the method for subsampling the model simulations penetrates 

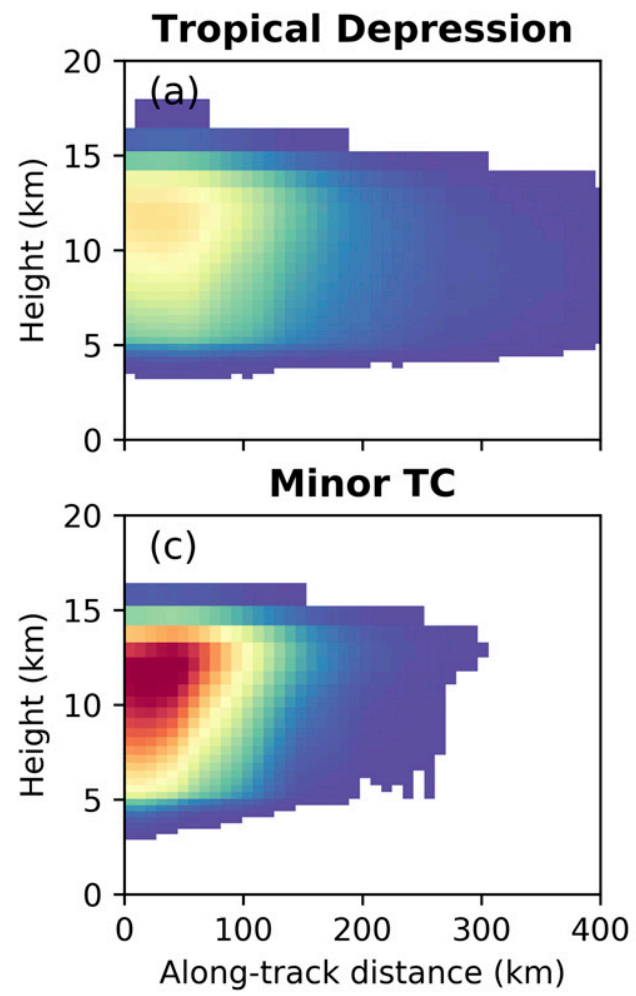

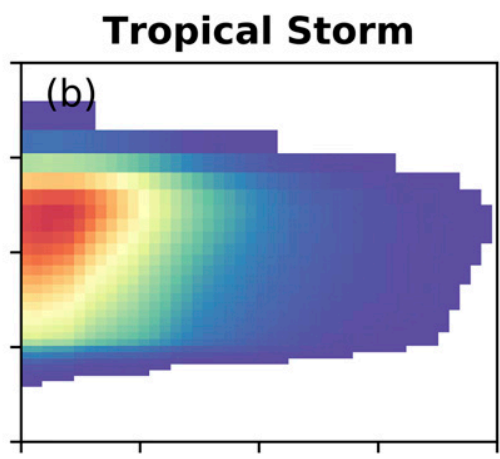

Major TC

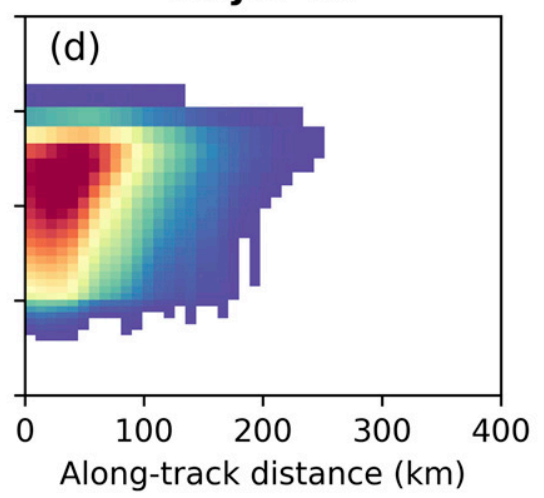

$\left(\mathrm{mg} / \mathrm{m}^{\wedge} 3\right)$

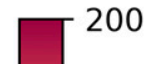

175

150

$-125$

100

75

50

$-25$

FIG. 9. As in Fig. 5, but from the WRF simulations using the microphysical scheme of the Thompson scheme.

through the TC center, as noted in section 2. To ensure that this distinct difference is due to the differences in sampling, we repeat the same analysis for model simulations but apply the CloudSat-footprint-like slicing method proposed in section 2.

Figure 7 shows composites of simulated IWC after the application of the CloudSat-like slicing method. The magnitude of maximum IWC is $\sim 150$ and $210 \mathrm{mg} \mathrm{m}^{-3}$ in the categories of minor and major TC, respectively, which is $\sim 20 \%$ less than the observed IWC. However, in the categories of TD and TS, the averaged IWC in simulations is $\sim 40 \%$ less than the observed IWC. In terms of the radial distribution, the simulated IWC extends to the zero ordinate, similar to the observed IWC, while its maximum is located at the RMW in minor and major TCs. Considering the vertical distribution, the altitude of the simulated IWC maxima are too low (just above the freezing level). This might be due to the 6-class single-moment microphysical scheme or the specified environment used by the model, which tends to produce less IWC in the upper level than observations.

After applying the CloudSat-like slicing method for simulated IWC, the distribution of simulated IWC appear to be more consistent with the observed IWC in CloudSat measurements, while the magnitude of simulated IWC is, on average, $\sim 25 \%$ less than the observed IWC.

\section{c. Nonprecipitating IWC}

A more complex method to inspect the vertical distribution of frozen hydrometeors involves separating IWC into the precipitating and nonprecipitating IWC to examine how the two types of IWC are distributed in TCs. Previous studies have demonstrated that precipitating IWC accounts for more than $80 \%$ of the total IWC when examined over all types of convective systems (Waliser et al. 2009; Chen et al. 2011; Deng et al. 2018). Accordingly, we focus our analysis on nonprecipitating IWC. Waliser et al. (2009) utilized precipitating conditions to distinguish between the two types of frozen hydrometeors. We used the same method to differentiate nonprecipitating IWC from the IWC in CloudSat measurements, and then compare with those from the WRF simulations.

In composites of CloudSat measurements (Fig. 8), the spatial characteristics of nonprecipitating IWC are similar to what were shown in the total IWC, while the average is only of about $10 \%-15 \%$ of the total IWC. Nonprecipitating IWC is concentrated at $8-13 \mathrm{~km}$, which is $3 \mathrm{~km}$ higher than that of total IWC. For model simulations, the amount of nonprecipitating IWC is also about $15 \%$ of the total IWC, with the maximum at around $8-14 \mathrm{~km}$ (see Fig. S3). Compared to CloudSat measurements, WRF simulates comparable amounts of nonprecipitating IWC, with a slightly higher cloud top in the WRF simulations. These results suggest that the WRF Model is able to qualitatively capture both the amount and distribution of the observed nonprecipitating IWC.

\section{d. Results with a different microphysics scheme}

In the aforementioned analyses, we found that the WRF Model can reasonably reproduce the magnitude and distribution of cloud ice in TCs. However, the production of cloud ice in a full physics model is regulated mainly by the microphysics scheme. The choice of scheme may change the result of simulations (Bao et al. 2012; Alvey et al. 2015; Fovell et al. 2016) 

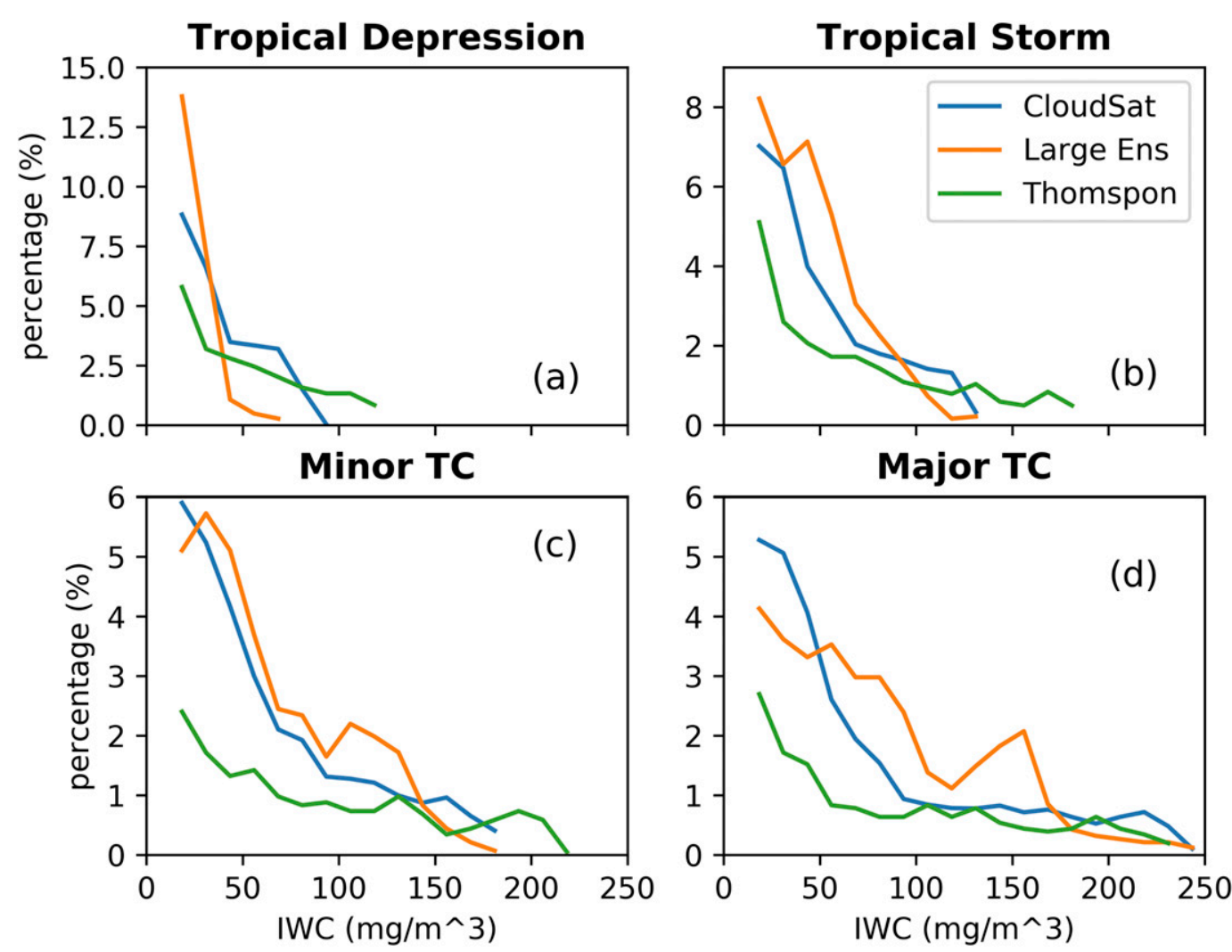

FIG. 10. The probability density function of IWC $\left(\mathrm{mg} \mathrm{m}^{-3}\right)$ for (a) TDs, (b), TSs, (c) minor TCs, and (d) major TCs, with bins of $12.5 \mathrm{mg} \mathrm{m}^{-3}$. The blue line is for CloudSat observations, the orange line is for the large ensemble simulations, and the green line is for the small ensemble using the Thompson scheme. The $y$ axis is the percentage of total grid.

and, therefore, previous conclusions may be affected if we use a different microphysics scheme. To address this concern, we produced an additional small ensemble of simulations using the Thompson scheme (Thompson et al. 2008), and used the CloudSat-like slicing method to evaluate the performance of the WRF Model in reproducing IWC.

Composites of IWC are made for the simulations using the Thompson scheme (Fig. 9). For all intensity categories, IWC is on average $\sim 30 \%$ greater than the original ensemble simulations, which use WSM6. In intensity categories of TD and TS, IWC in the Thompson scheme is 3 times greater, while it is $50 \%$ greater for minor and major TCs, compared with original simulations. In terms of distribution of IWC, the extent is similar between two microphysical schemes, concentrating at the eyewall; however, the Thompson scheme produces a greater amount of IWC at higher altitudes and a narrower ring, compared with WSM6.

We also compared the simulations using the Thompson scheme with CloudSat observations. The values of the simulated IWC maxima are $\sim 20 \%$ greater than observed, and the radial location almost touches the PCA. The extent of IWC is also relatively compact compared with CloudSat observations, although this may be due to the narrow distribution of TC size in the small ensemble. One clear difference is that the radial extent of large IWC increases with height, while the observed IWC decreases with height, which may reflect the tendency for the Thompson scheme tends to over produce IWC, especially nonprecipitating IWC (Varble et al. 2014).

To quantitatively compare the simulated IWC with the observed IWC, we examined the probability density function of IWC within $400 \mathrm{~km}$ of the PCA for the large ensemble simulations, the small ensemble using the Thompson scheme, and CloudSat observations, separating into four intensity categories (Fig. 10). The threshold is from 0 to $250 \mathrm{mg} \mathrm{m}^{-3}$ with a bin interval of $12.5 \mathrm{mg} \mathrm{m}^{-3}$. The relative distributions between three sets are similar for all four intensity categories. Consider the intensity category of TS as an example (Fig. 10b). For the smallest bin (0-12.5 $\left.\mathrm{mg} \mathrm{m}^{-3}\right)$, CloudSat observations and the large ensemble simulations have $\sim 70 \%$ falling into this bin, whereas the Thompson ensemble has a higher percentage of $\sim 82 \%$ (not shown). For small to medium IWC below $87.5 \mathrm{mg} \mathrm{m}^{-3}$, the large ensemble simulations have the highest percentage while the Thompson ensemble is the lowest. For the large magnitudes of IWC above $87.5 \mathrm{mg} \mathrm{m}^{-3}$, the Thompson ensemble has the highest percentage and the large ensemble simulations have the lowest. In addition, the Thompson ensemble has the largest maxima of $175 \mathrm{mg} \mathrm{m}^{-3}$ among all sets, whereas CloudSat observations and the large ensemble simulations have the maxima of $125 \mathrm{mg} \mathrm{m}^{-3}$, consistent with a previous study suggesting that the Thompson scheme tends to produce more cloud ice (Varble et al. 2014). The analysis using the 

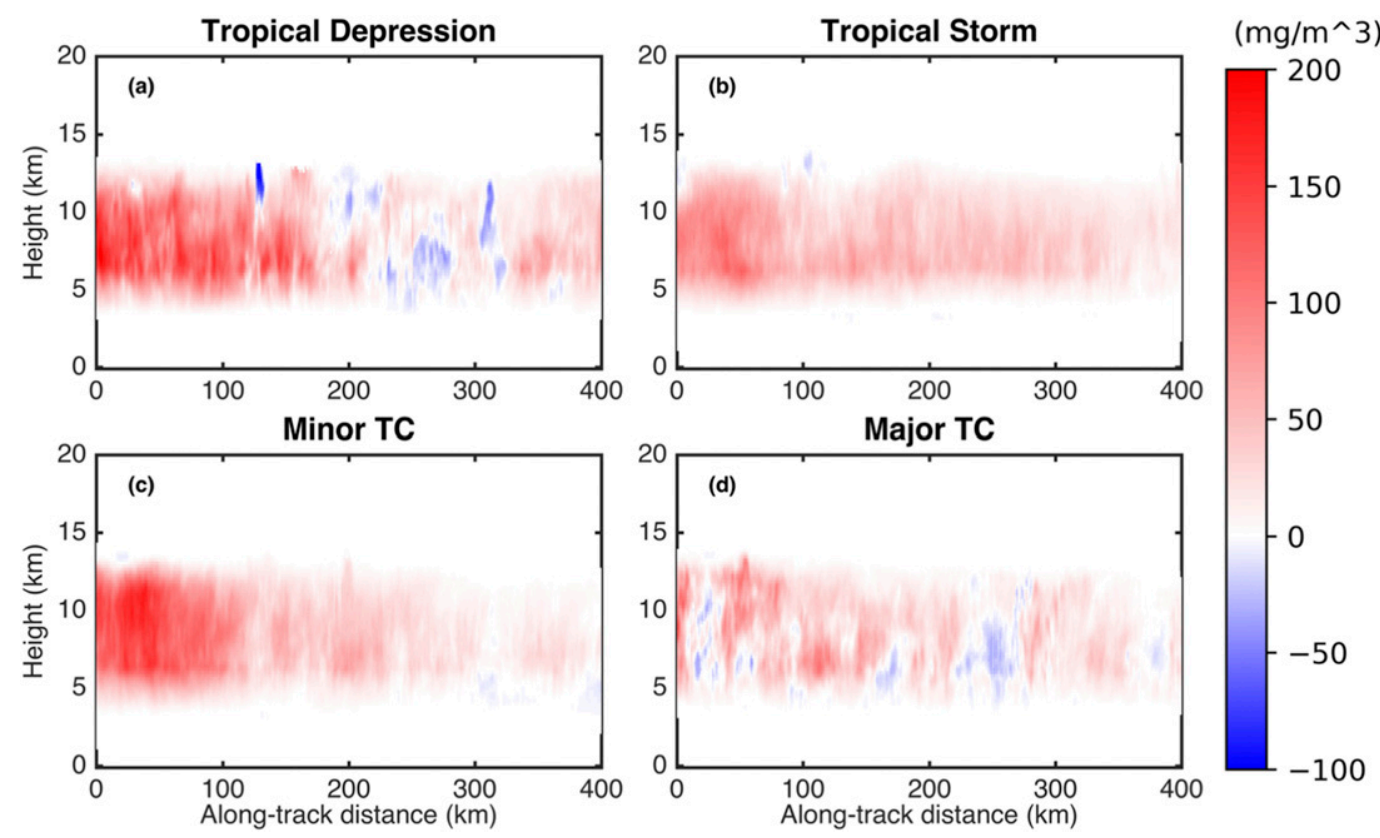

$\left(\mathrm{mg} / \mathrm{m}^{\wedge} 3\right)$

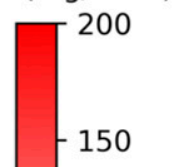

$-100$

50

FIG. 11. Difference in IWC (shading; $\mathrm{mg} \mathrm{m}^{-3}$ ) of the CloudSat measurements between intensifying and weakening TCs for (a) TDs, (b) TSs, (c) minor TCs, and (d) major TCs. The $x$ axis is the radius to PCA in km and the $y$ axis is height in $\mathrm{km}$. probability density function suggests that the production of IWC in WRF is dominated mainly by the choice of microphysical schemes: the 6-class single-moment scheme tends to produce fewer large values of IWC, while the Thompson scheme is likely to produce more large values of IWC, compared to the CloudSat observations.

\section{Can WRF capture the signal of TC intensification?}

Latent heating is important in determining the evolution of TC intensity (Schubert and Hack 1982; Hack and Schubert 1986; Nolan et al. 2007). The results above show that frozen hydrometeor concentration can serve as a proxy for latent heat release. Here we examine whether the simulated IWC also reproduces the observed signal that precede $\mathrm{TC}$ intensity change found by $\mathrm{Wu}$ and Soden (2017).

\section{a. IWC}

Previous analyses of CloudSat measurements found that intensifying TCs tend to have greater IWC than that of weakening TCs (Wu and Soden 2017). To examine whether the WRF Model reproduces this signal, we create composites of CloudSatmeasured IWC for intensifying $\left(>2.57 \mathrm{~m} \mathrm{~s}^{-1} ; 5 \mathrm{kt}\right)$ and weakening TCs $\left(<-2.57 \mathrm{~m} \mathrm{~s}^{-1} ;-5 \mathrm{kt}\right)$. Figure 11 shows the difference in IWC between intensifying and weakening TCs: for all intensity categories, intensifying TCs have greater IWC than weakening TCs throughout the whole domain, with the largest differences within $100 \mathrm{~km}$ of the PCA, except for major TC which is not as uniform. The reason may be partly due to a stronger TC intensity in weakening major TCs, which undermines the IWC signal.
We apply the CloudSat-like slicing method to sample the WRF simulations, and then compare results from the WRF simulations to CloudSat measurements. The WRF Model shows the same pattern of TC intensification as the CloudSat measurements. That is, the increasing IWC in intensifying TCs is throughout the whole domain, except for major TC (Fig. 12). In terms of the magnitude in WRF simulations, the difference in areal mean IWC between intensifying and weakening is only about half of the difference found in CloudSat measurements for TD, TS, and minor TC. For minor TC, the clear positive differences in IWC are only within $150 \mathrm{~km}$ of the PCA, and this distribution is slightly different from CloudSat, where the positive signal is distributed throughout the entire $500 \mathrm{~km}$ of the PCA. However, for major TCs, the WRF simulations have negative differences in most of the region, and this is inconsistent with those in the CloudSat measurements. The unclear signature outside $150 \mathrm{~km}$ in minor and major TC might be due to the drying effect on the environment when the TC is developing in an idealized simulation. In previous studies using an idealized model framework, the mean state of the atmosphere has been shown to become drier as tropical convective systems develop (Wing and Emanuel 2014; Wing and Cronin 2016), and this dry environment could result in less production of cloud ice outside TC inner core. As the CloudSat-like slicing method samples the area that is outside TC inner core, this drying effect may substantially influence the composites of IWC, leading to negative values in differences between composites for intensifying and weakening TCs.

We repeat the same analysis for the azimuthally averaged IWC to better understand physical processes that regulate TC intensification. The areal mean IWC is also greater in 

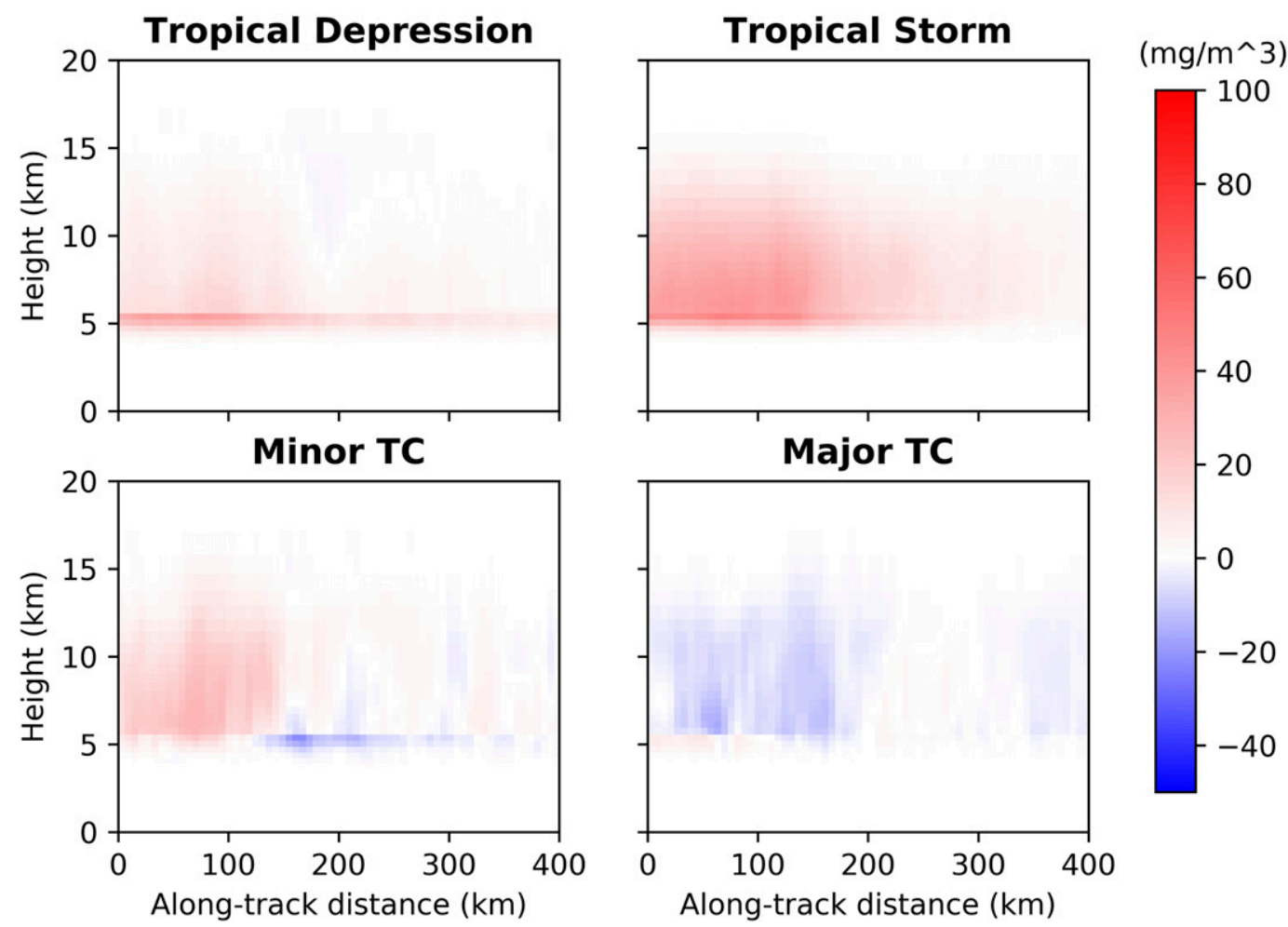

FIG. 12. Difference in IWC (shading; $\mathrm{mg} \mathrm{m}^{-3}$ ) of the WRF Model between intensifying and weakening TCs using the CloudSat-like slicing method for (a) TDs, (b) TSs, (c) minor TCs, and (d) major TCs. The $x$ axis is the radius to the TC center in $\mathrm{km}$ and the $y$ axis is height in $\mathrm{km}$.

intensifying TCs for all intensity categories. However, the distribution of greater IWC in intensifying TCs differs from those using the CloudSat-like slicing method: for TD and TS (Figs. 13a,b), intensifying TCs possess higher IWC throughout the entire TC, yet for minor and major TC (Figs. 13c,d), a dipole pattern appears in the inner core, such that the difference in IWC is negative near the TC center, and positive outside the $50 \mathrm{~km}$ radius. The dipole pattern may be caused by different TC sizes between intensifying and weakening TCs, or the intensifying TC eyewall getting stronger and moister, and the eye getting drier. To verify the reason for the dipole pattern, we perform the same analysis but for composites with the axial distance normalized by RMW (Fig. S4). It is shown that intensifying TCs have a greater IWC around the radius of one RMW for minor and major TC. This indicates that the eyewall in intensifying TCs is stronger, resulting in a greater amount of IWC. On the other hand, a previous study using airborne Doppler observations found that intensifying TCs generally have a smaller RMW compared to TCs in steady state (Rogers et al. 2013). In the ensemble simulations, intensifying minor and major TCs have, on average, $10 \mathrm{~km}$ larger RMW than weakening TCs (supplementary Table 1). The outward displacement of eyewall in intensifying TCs may lead to less cloud ice production within the $50 \mathrm{~km}$ radius, while we cannot rule out the possibility that intensifying TCs have a moister eyewall and a drier eye. The variation of RMW along with intensity change seems opposite to previous studies, where RMW tends to be negatively correlated with intensity change. However, the comparison in the ensemble simulations was executed for the same intensity categories, which is an important factor in regulating TC size, while previous studies performed the comparison across the entire spectrum of intensity categories. Consequently, the dipole pattern and the displacement of eyewall in minor and major TC suggests that using the areal mean IWC within certain radius of the TC center may reduce the signal of TC intensification.

We further extend the lead time up to $24 \mathrm{~h}$ before the intensity change, to inspect how early the signal of intensification occurs. We compute the 6-h intensity change from 0-6 to 6-12 to $12-18$ to $18-24 \mathrm{~h}$ after the simulated timeframe, and then sort into intensifying and weakening TCs for 6-, 12-, 18-, and 24-h lead times. Figure 14 shows the areal mean IWC for intensifying and weakening TCs at four different lead times and for four intensity categories. For 6-h lead time, the areal mean IWC of intensifying TCs is greater than that of weakening TCs, consistent with the aforementioned signal of TC intensification. However, for lead times greater than $6 \mathrm{~h}$, the differences between intensifying and weakening TCs are not as clear. This differs substantially from the observed signal of TC intensification in the amount of cloud ice, in which the signal occurs all the way up to 24-h lead time (Wu and Soden 2017; see Fig. S5). Possible reasons might be due to the magnitude differences of modeled IWC or a lack of environmental variability in the idealized simulations, which may affect the signal in a longer forecasting time. 

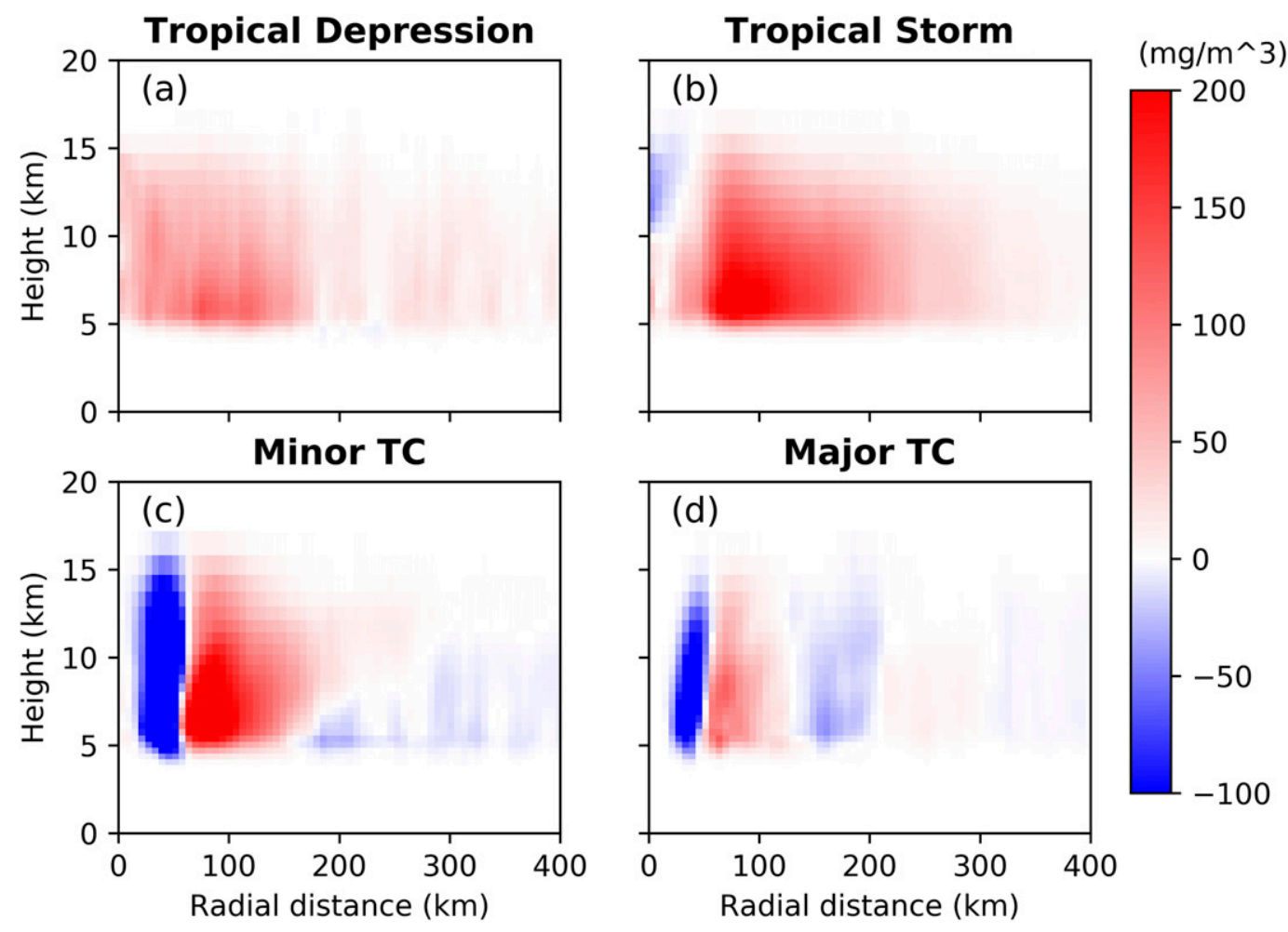

FIG. 13. As in Fig. 12, but for the azimuthal mean composites.

\section{b. IWP}

We create composites of IWP from the SPARE-ICE for intensifying and weakening TCs to examine their differences in the horizontal distribution of frozen hydrometeors. On average, intensifying TCs have a greater mean IWP than weakening TCs for all intensity categories, although the differences are small for major TC. We further evaluate the distribution of their differences by subtracting composites for weakening TCs from those for intensifying TCs using a shear-relative framework. Figure 15 shows that intensifying TCs have greater IWP in most of the areas within $200 \mathrm{~km}$ radius for TD and TS. However, for minor and major TC, intensifying TCs still have more areas with large IWP than weakening TCs (the ratio of positive to negative differences is 5:2 for minor TC and 5:3 for major TC), although the differences in IWP are not as systematic throughout the domain. This result is generally consistent with previous observational studies that suggest that intensifying TCs tend to have a greater amount of convection than weakening TCs (Zagrodnik and Jiang 2014; Tao and Jiang 2015; Harnos and Nesbitt 2016).

We repeat the same analysis for the WRF-simulated IWP to examine whether the observed signal of TC intensification also occurs in the simulated IWP. In the WRF simulations, intensifying TCs have a greater mean IWP than weakening TCs for all intensity categories. Figure 16 shows that the greater IWP in intensifying TCs is distributed with a similar extent as that in the SPARE-ICE: in TD and TS, the greater IWP in intensifying TCs is throughout the whole domain; in minor TC, however, IWP in intensifying TCs is smaller at the region of
$30-60 \mathrm{~km}$ radius, but becomes greater at the region of 70 $200 \mathrm{~km}$ radius, compared with weakening TCs. Again, this might be due to different TC sizes between intensifying and weakening TCs, or/and a stronger eyewall in intensifying TCs,

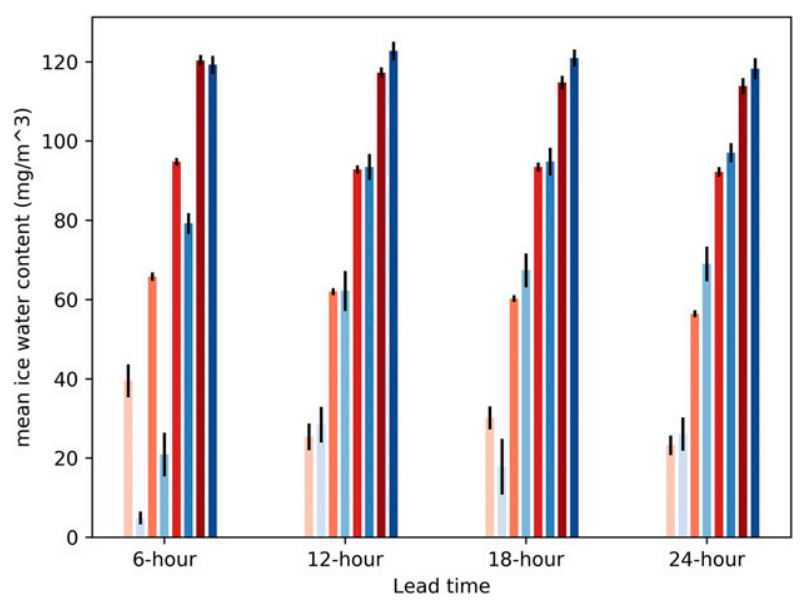

FIG. 14. The areal mean IWC for each category of storm intensity as a function of lead time from the WRF simulations. Red and blue bars are the areal mean of IWC for intensifying and weakening TCs, respectively. The different brightness represents different categories of TC intensity: tropical depression, tropical storms, and minor and major TCs (from light to dark). Error bars are the standard error. The results are grouped by lead time: $6,12,18$, and $24 \mathrm{~h}$ (in sequence, from left to right). 


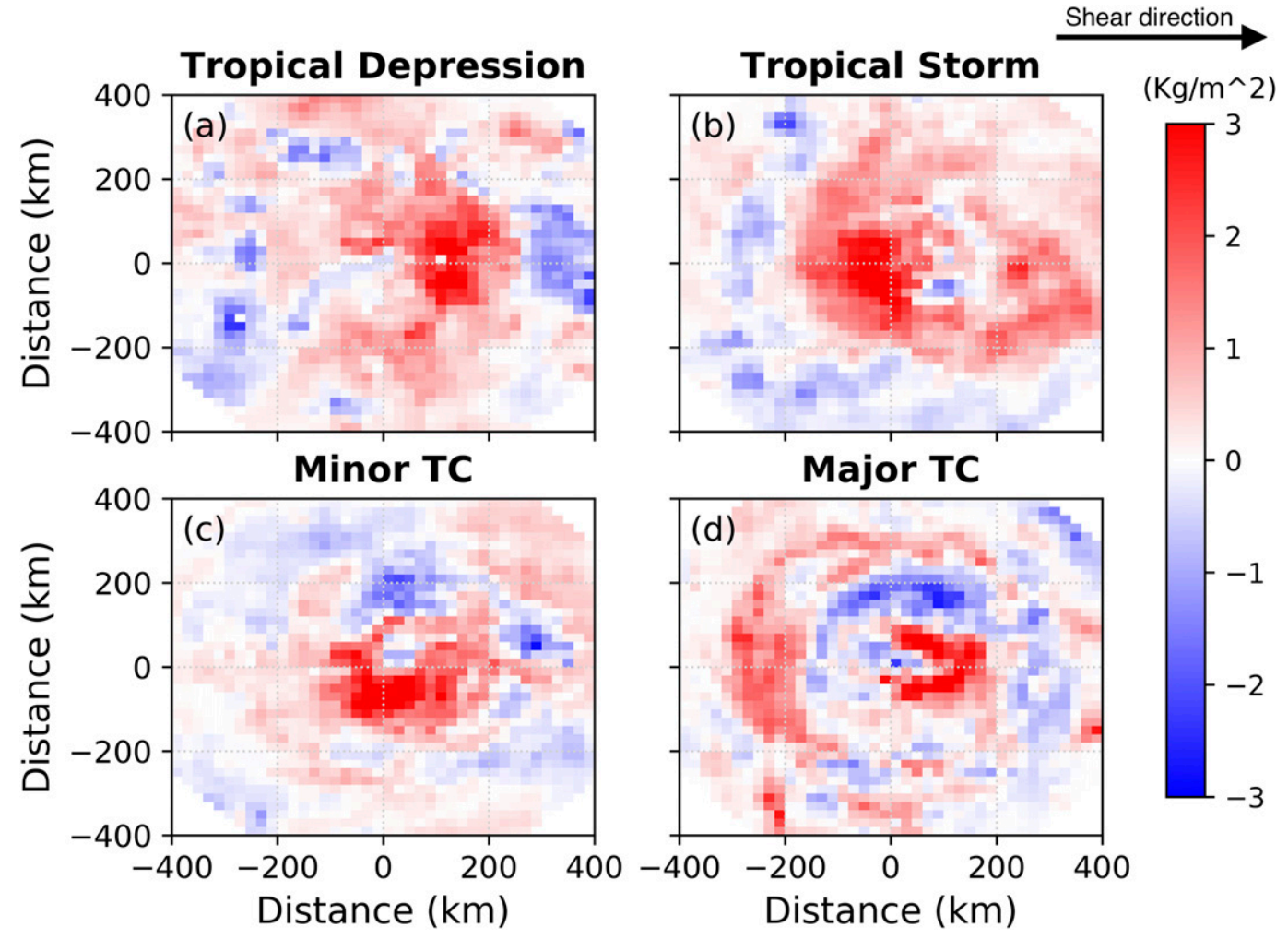

FIG. 15. Difference in IWP (shading; $\mathrm{kg} \mathrm{m}^{-2}$ ) of the SPARE-ICE between intensifying and weakening TCs for (a) TDs, (b) TSs, (c) minor TCs, and (d) major TCs. The $x$ and $y$ axes are the radius to the TC center in $\mathrm{km}$. The direction of the vertical wind shear is toward the right of the figure.

similar to the dipole pattern related to simulated IWC in a previous discussion.

Another similarity between the SPARE-ICE and WRFsimulated IWP is the difference in azimuthal distribution between intensifying and weakening TCs. Except for TD, the greater IWP in intensifying TCs is at the same shear-relative quadrant. Previous passive satellite studies suggested that the major difference in horizontal IWP between intensifying and weakening TCs mainly occurs at the upshear quadrants of the TC (Alvey et al. 2015; Fischer et al. 2018), while Figs. 15 and 16 show that only TS and minor TC in the SPACE-ICE and TD and TS in the WRF demonstrate the major difference at the upshear quadrants.

\section{Discussion}

In this study, we examined how the evolution of latent heating is related to IWC and the ability of the WRF Model to simulate IWC and its relationship with TC intensification shown in satellite measurements. We found that only the latent heating in the mid- to upper levels displays temporally asymmetric evolution relative to the time of the LMI, overlapping with the area of high energy transformation efficiency noted in Nolan et al. (2007). The evolution of latent heating in the midto upper levels suggests that latent heat release in $500-300 \mathrm{hPa}$ not only can be efficiently utilized by TCs, but also plays an important role in modulating the evolution of TC intensity compared to latent heat release at other levels. Although Nolan et al. (2019) suggested that total condensates above $10 \mathrm{~km}$ have a relatively low correlation coefficient with TC intensity change of $\sim 0.4$, these results imply that IWC at $6-10 \mathrm{~km}$ could potentially be used to predict future TC intensification.

Nevertheless, this study does not aim to develop an algorithm that can be applied for the operational forecasting. One possibility is to use the normalization method noted in Fischer et al. (2018), which minimizes the effect from TC intensity and enlarge the signal of TC intensification. It is worth noting that the idealized WRF Model does not include all ranges of variability in the real atmosphere such as environmental humidity, even though the wind shear is changed incrementally in these ensemble simulations. Because the distribution of sample sizes is different between CloudSat measurements and WRF simulations regarding respective intensity change categories, this might affect results shown in this study. Regardless, the physical processes and mechanisms found in these ensemble simulations still provide valuable insights for TC research.

The similarity between the evolution of latent heating and frozen hydrometeors suggests that frozen hydrometeors can be an important predictor in statistical models of TC intensity. For dynamical models, observations of IWC can provide useful information for evaluating model simulations of latent heat release. 


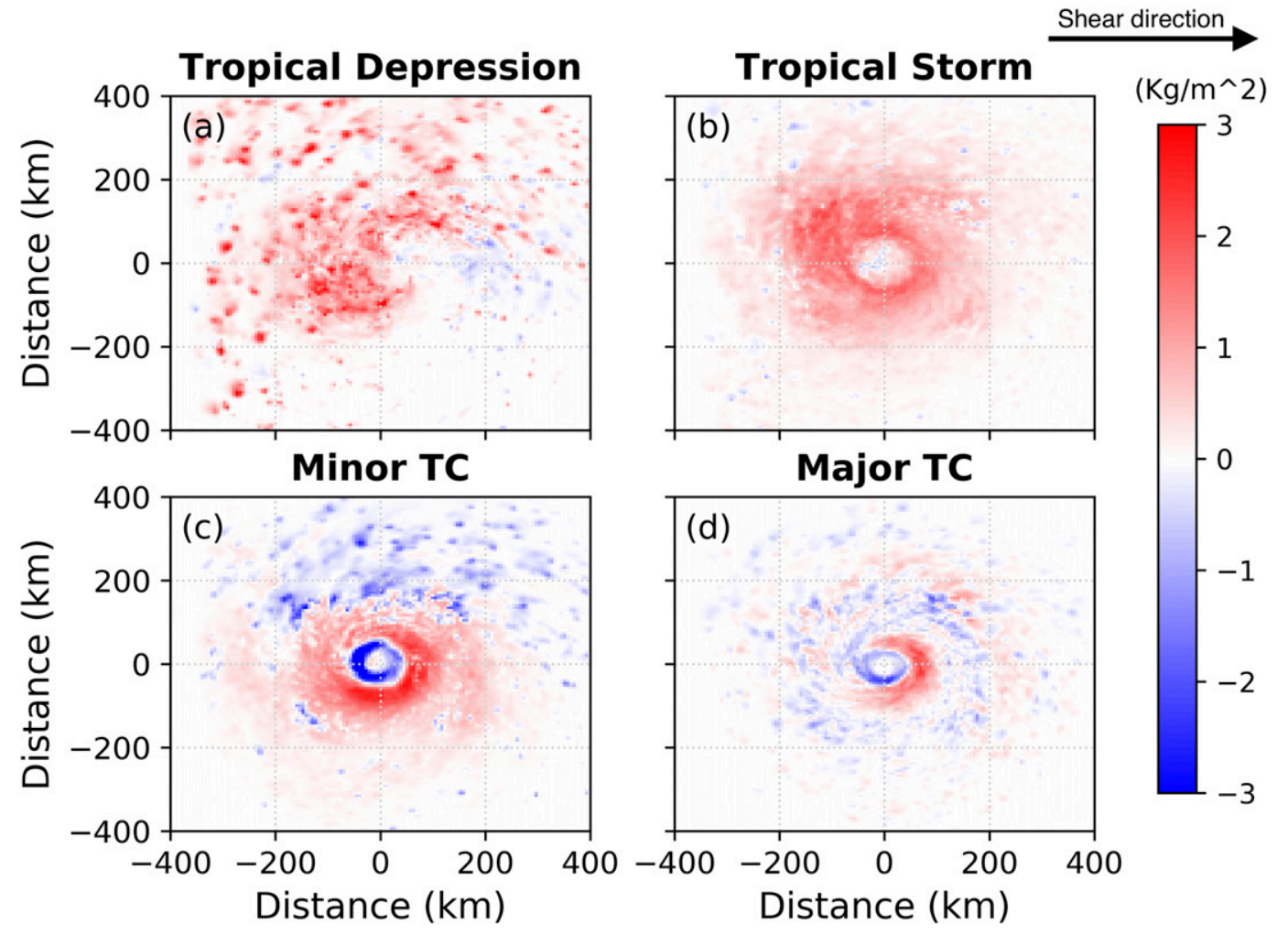

FIG. 16. As in Fig. 15, but for the WRF simulations.

The comparison between the simulated IWC and observed IWC suggests that the WRF Model can reasonably reproduce the magnitude of IWC and appropriately replicate the distribution of IWC. Comparing the large ensemble simulations with CloudSat observations, the simulated IWC values in TD and TS are too small and the altitudes of the simulated IWC maxima are too low. On the other hand, using the Thompson scheme, the simulated IWC values are $\sim 20 \%$ greater than observations and the altitudes of the IWC maxima are too high. These opposing results suggest that the choice of microphysics scheme substantially impacts the amount of IWC in the WRF Model, such that it is hard to discern the true causes of the discrepancies between simulations and observations.

The signal of a greater areal mean frozen hydrometeor concentration for intensifying TCs is found in both satellite observations and model simulations. This conclusion is consistent with previous studies that found a signal of TC intensification in passive microwave satellite and lightning measurements (Harnos and Nesbitt 2011, 2016; Wu and Soden 2017; Stevenson et al. 2018). Yet, some studies showed that the increase of frozen hydrometeors is the consequence of the increase in TC intensity, rather than the precursor (Tao and Jiang 2015; Fischer et al. 2018). The different conclusion might be due to the fact that the 37 and $85 \mathrm{GHz}$ microwave channels have a much greater sensitivity to liquid water and larger ice particles than smaller ice particles in the upper troposphere. Two weaknesses in the WRF results are 1) the less difference in IWC between intensifying and weakening TCs, and 2) the failure to replicate the signal of TC intensification up to a 24-h lead time. We speculate that these might be due to the barely acceptable magnitude of modeled IWC or a lack of influences from environment in idealized simulations.

On the other hand, the WRF simulates the ring-like structure of IWP, whereas the SPARE-ICE seems to miss the eyewall structure. One possible explanation is that the SPARE-ICE is unable to identify the TC eyewall due to its coarse resolution. Another possibility is that TC centers in the SPARE-ICE slightly differ from their true centers, so that the eyewall blurs after compositing hundreds of cases. In addition, WRF demonstrates a negative-inside, positive-outside pattern in the difference between intensifying and weakening TCs, while such a pattern is not observed in the SPARE-ICE. We speculate that the pattern in the WRF simulations is caused by the displacement of the eyewall between intensifying and weakening TCs. Outside of this aspect, the WRF Model can successfully reproduce the distribution of frozen hydrometeors and qualitatively capture their magnitudes in the satellite observations, although there is plenty of room for improvement considering its mixed performance discussed above.

\section{Conclusions}

We examined the relationship between latent heating and frozen hydrometeors, the ability of the WRF Model to reproduce the observed frozen hydrometeors in TCs, and the signature of TC intensification in satellite-based as well as simulated metrics. We found the following: 
- Upper-level $(6-10 \mathrm{~km})$ latent heat release might play a key role in governing the evolution of TC intensity.

- In the WRF Model, IWP is correlated with latent heating in the mid- to high troposphere, and thus has a potential to serve as a proxy of latent heating in this level.

- The WRF Model reasonably reproduced the magnitude and distribution of the observed frozen hydrometeors, with $\sim 20 \%$ deviation from observational metrics, suggesting that the model still appears to have microphysical deficiencies that needed to be improved.

- The enhancement of frozen hydrometeors in intensifying TCs is found in both the satellite-based and simulated metrics, though the model only captures the observed signal up to 6-h lead time.

- The dipole pattern occurs in the difference between composites of intensifying and weakening TCs, indicating that a simple domain average of frozen hydrometeors is likely to obscure the clarity of the signal of TC intensification.

- Further investigations are required to examine the cause of the increasing frozen hydrometeors in intensifying TCs, and to explore how to utilize this signal to better predict future TC intensity.

Acknowledgments. The authors acknowledge three anonymous reviewers whose comments led to substantial improvements of this paper. This work is supported by a grant from the NASA CloudSat/CALIPSO Science Team program, and NASA Award 80 NSSC18K1032. SB's contribution was supported by the German Federal Ministry of Education and Research (BMBF), under project $\mathrm{HD}(\mathrm{CP})^{2}$, Grants $01 \mathrm{LK} 1502 \mathrm{~B}$ and $01 \mathrm{LK} 1505 \mathrm{D}$, and contributes to Excellence Cluster EXC 2037 'Climate", Climatic Change, and Society," Grant 390683824 of the German Research Foundation (DFG), and to the Center for Earth System Research and Sustainability (CEN) of Universität Hamburg. YM was supported by Japan Society for the Promotion of Science (JSPS) Scientific Research 26-358 for the JSPS fellowship program for overseas researchers and JSPS KAKENHI Grant JP18H05872.

\section{REFERENCES}

Alvey, G. R., III, J. Zawislak, and E. Zipser, 2015: Precipitation properties observed during tropical cyclone intensity change. Mon. Wea. Rev., 143, 4476-4492, https://doi.org/10.1175/ MWR-D-15-0065.1.

Austin, R. T., A. J. Heymsfield, and G. L. Stephens, 2009: Retrieval of ice cloud microphysical parameters using the CloudSat millimeter-wave radar and temperature. J. Geophys. Res., 114, D00A23, https://doi.org/10.1029/2008JD010049.

Bao, J., S. G. Gopalakrishnan, S. A. Michelson, F. D. Marks, and M. T. Montgomery, 2012: Impact of physics representations in the HWRFX on simulated hurricane structure and pressurewind relationships. Mon. Wea. Rev., 140, 3278-3299, https:// doi.org/10.1175/MWR-D-11-00332.1.

Cecil, D. J., and E. J. Zipser, 1999: Relationships between tropical cyclone intensity and satellite-based indicators of inner core convection: $85-\mathrm{GHz}$ ice-scattering signature and lightning. Mon. Wea. Rev., 127, 103-123, https://doi.org/10.1175/15200493(1999) $127<0103$ :RBTCIA $>2.0$. CO;2.

Chen, W.-T., C. P. Woods, J.-L. F. Li, D. E. Waliser, J.-D. Chern, W.-K. Tao, J. H. Jiang, and A. M. Tompkins, 2011: Partitioning
CloudSat ice water content for comparison with upper tropospheric ice in global atmospheric models. J. Geophys. Res., 116, D19206, https://doi.org/10.1029/2010JD015179.

Corbosiero, K. L., and J. Molinari, 2003: The relationship between storm motion, vertical wind shear, and convective asymmetries in tropical cyclones. J. Atmos. Sci., 60, 366-376, https://doi.org/ 10.1175/1520-0469(2003)060<0366:TRBSMV > 2.0.CO;2.

DeHart, J. C., R. A. Houze, and R. F. Rogers, 2014: Quadrant distribution of tropical cyclone inner-core kinematics in relation to environmental shear. J. Atmos. Sci., 71, 2713-2732, https://doi.org/10.1175/JAS-D-13-0298.1.

DeMaria, M., and J. Kaplan, 1994: A Statistical Hurricane Intensity Prediction Scheme (SHIPS) for the Atlantic basin. Wea. Forecasting, 9, 209-220, https://doi.org/10.1175/1520-0434(1994) 009<0209:ASHIPS $>2.0 . \mathrm{CO} ; 2$.

—, M. Mainelli, L. K. Shay, J. A. Knaff, and J. Kaplan, 2005: Further improvements to the Statistical Hurricane Intensity Prediction Scheme (SHIPS). Wea. Forecasting, 20, 531-543, https://doi.org/10.1175/WAF862.1.

Deng, M., G. G. Mace, Z. Wang, and H. Okamoto, 2010: Tropical Composition, Cloud and Climate Coupling Experiment validation for cirrus cloud profiling retrieval using CloudSat radar and CALIPSO lidar. J. Geophys. Res. Atmos., 115, D00J15, https://doi.org/10.1029/2009JD013104.

,,--- - J. F. Li, and Y. Luo, 2018: Partitioning ice water content from retrievals and its application in model comparison. J. Atmos. Sci., 75, 1105-1120, https://doi.org/ 10.1175/JAS-D-17-0017.1.

Emanuel, K. A., C. DesAutels, C. Holloway, and R. Korty, 2004: Environmental control of tropical cyclone intensity. J. Atmos. Sci., 61, 843-858, https://doi.org/10.1175/1520-0469(2004) 061<0843:ECOTCI > 2.0.CO;2.

Fischer, M. S., B. H. Tang, K. L. Corbosiero, and C. M. Rozoff, 2018: Normalized convective characteristics of tropical cyclone rapid intensification events in the North Atlantic and eastern North Pacific. Mon. Wea. Rev., 146, 1133-1155, https:// doi.org/10.1175/MWR-D-17-0239.1.

Fovell, R. G., Y. P. Bu, K. L. Corbosiero, W. Tung, Y. Cao, H. Kuo, L. Hsu, and H. Su, 2016: Influence of cloud microphysics and radiation on tropical cyclone structure and motion. Multiscale Convection-Coupled Systems in the Tropics: A Tribute to Dr. Michio Yanai, Meteor. Monogr., No. 56, Amer. Meteor. Soc., https://doi.org/10.1175/AMSMONOGRAPHS-D-15-0006.1.

Hack, J. J., and W. H. Schubert, 1986: Nonlinear response of atmospheric vortices to heating by organized cumulus convection. J. Atmos. Sci., 43, 1559-1573, https://doi.org/10.1175/ 1520-0469(1986)043<1559:NROAVT>2.0.CO;2.

Harnos, D. S., and S. W. Nesbitt, 2011: Convective structure in rapidly intensifying tropical cyclones as depicted by passive microwave measurements. Geophys. Res. Lett., 38, L07805, https://doi.org/10.1029/2011GL047010.

- , and -2016 : Passive microwave quantification of tropical cyclone inner-core cloud populations relative to subsequent intensity change. Mon. Wea. Rev., 144, 4461-4482, https:// doi.org/10.1175/MWR-D-15-0090.1.

Hence, D. A., and R. A. Houze, 2012: Vertical structure of tropical cyclone rainbands as seen by the TRMM Precipitation Radar. J. Atmos. Sci., 69, 2644-2661, https://doi.org/10.1175/JAS-D11-0323.1.

Hendricks, E. A., M. S. Peng, B. Fu, and T. Li, 2010: Quantifying environmental control on tropical cyclone intensity change. Mon. Wea. Rev., 138, 3243-3271, https://doi.org/10.1175/ 2010MWR3185.1. 
Holl, G., S. Eliasson, J. Mendrok, and S. A. Buehler, 2014: SPAREICE: Synergistic ice water path from passive operational sensors. J. Geophys. Res. Atmos., 119, 1504-1523, https:// doi.org/10.1002/2013JD020759.

Hong, S.-Y., and J.-O. J. Lim, 2006: The WRF Single-Moment 6-class microphysics scheme (WSM6). J. Korean Meteor. Soc., 42, 129-151.

Jin, Y., and Coauthors, 2014: The impact of ice phase cloud parameterizations on tropical cyclone prediction. Mon. Wea. Rev., 142, 606-625, https://doi.org/10.1175/MWR-D-13-00058.1.

Kaplan, J., and M. DeMaria, 2003: Large-scale characteristics of rapidly intensifying tropical cyclones in the North Atlantic basin. Wea. Forecasting, 18, 1093-1108, https://doi.org/10.1175/ 1520-0434(2003)018<1093:LCORIT>2.0.CO;2.

,-- , and J. A. Knaff, 2010: A revised tropical cyclone rapid intensification index for the Atlantic and eastern North Pacific basins. Wea. Forecasting, 25, 220-241, https://doi.org/10.1175/ 2009WAF2222280.1.

Knapp, K. R., M. C. Kruk, D. H. Levinson, H. J. Diamond, and C. J. Neuman, 2010: The International Best Track Archive for Climate Stewardship (IBTrACS): Unifying tropical cyclone data. Bull. Amer. Meteor. Soc., 91, 363-376, https://doi.org/ 10.1175/2009BAMS2755.1.

McFarquhar, G. M., H. Zhang, G. Heymsfield, J. B. Halverson, R. Hood, J. Dudhia, and F. Marks, 2006: Factors affecting the evolution of Hurricane Erin (2001) and the distributions of hydrometeors: Role of microphysical processes. J. Atmos. Sci., 63, 127-150, https://doi.org/10.1175/JAS3590.1.

Miyamoto, Y., and D. S. Nolan, 2018: Structural changes preceding rapid intensification in tropical cyclones as shown in a large ensemble of idealized simulations. J. Atmos. Sci., 75, 555-569, https://doi.org/10.1175/JAS-D-17-0177.1.

Montgomery, M. T., and R. J. Kallenbach, 1997: A theory for vortex Rossby-waves and its application to spiral bands and intensity changes in hurricanes. Quart. J. Roy. Meteor. Soc., 123, 435-465, https://doi.org/10.1002/qj.49712353810.

Nolan, D. S., 2011: Evaluating environmental favorableness for tropical cyclone development with the method of pointdownscaling. J. Adv. Model. Earth Syst., 3, M08001, https:// doi.org/10.1029/2011MS000063.

—, Y. Moon, and D. P. Stern, 2007: Tropical cyclone intensification from asymmetric convection: Energetics and efficiency. J. Atmos. Sci., 64, 3377-3405, https://doi.org/ 10.1175/JAS3988.1.

—, Y. Miyamoto, S. Wu, and B. J. Soden, 2019: On the correlation between total condensate and moist heating in tropical cyclones and applications for diagnosing intensity. Mon. Wea. Rev., 147, 3759-3784, https://doi.org/10.1175/MWR-D-19-0010.1.

Reasor, P., R. Rogers, and S. Lorsolo, 2013: Environmental flow impacts on tropical cyclone structure diagnosed from airborne Doppler radar composites. Mon. Wea. Rev., 141, 2949-2969, https://doi.org/10.1175/MWR-D-12-00334.1.

Rogers, R., P. Reasor, and S. Lorsolo, 2013: Airborne Doppler observations of the inner-core structural differences between intensifying and steady-state tropical cyclones. Mon. Wea. Rev., 141, 2970-2991, https://doi.org/10.1175/MWR-D-12-00357.1.

Schubert, W. H., and J. J. Hack, 1982: Inertial stability and tropical cyclone development. J. Atmos. Sci., 39, 1687-1697, https://doi.org/10.1175/1520-0469(1982)039<1687:ISATCD> 2.0.CO;2.
—-, M. T. Montgomery, R. K. Taft, T. A. Guinn, S. R. Fulton, J. P. Kossin, and J. P. Edwards, 1999: Polygonal eyewalls, asymmetric eye contraction, and potential vorticity mixing in hurricanes. J. Atmos. Sci., 56, 1197-1223, https://doi.org/ 10.1175/1520-0469(1999)056<1197:PEAECA > 2.0.CO;2.

Stevenson, S. N., K. L. Corbosiero, M. DeMaria, and J. L. Vigh, 2018: A 10-year survey of tropical cyclone inner-core lightning bursts and their relationship to intensity change. Wea. Forecasting, 33, 23-36, https://doi.org/10.1175/WAF-D-170096.1.

Tao, C., and H. Jiang, 2015: Distributions of shallow to very deep precipitation-convection in rapidly intensifying tropical cyclones. J. Climate, 28, 8791-8824, https://doi.org/10.1175/JCLID-14-00448.1.

Thompson, G., R. M. Rasmussen, and K. Manning, 2004: Explicit forecasts of winter precipitation using an improved bulk microphysics scheme. Part I: Description and sensitivity analysis. Mon. Wea. Rev., 132, 519-542, https://doi.org/10.1175/15200493(2004)132<0519:EFOWPU>2.0.CO;2.

—, P. R. Field, R. M. Rasmussen, and W. D. Hall, 2008: Explicit forecasts of winter precipitation using an improved bulk microphysics scheme. Part II: Implementation of a new snow parameterization. Mon. Wea. Rev., 136, 5095-5115, https:// doi.org/10.1175/2008MWR2387.1.

Tourville, N., G. Stephens, M. DeMaria, and D. Vane, 2015: Remote sensing of tropical cyclones: Observations from CloudSat and A-Train profilers. Bull. Amer. Meteor. Soc., 96, 609-622, https://doi.org/10.1175/BAMS-D-13-00282.1.

Varble, A., and Coauthors, 2014: Evaluation of cloud-resolving and limited area model intercomparison simulations using TWPICE observations: 1. Deep convective updraft properties. J. Geophys. Res. Atmos., 119, 13 891-13 918, https://doi.org/ 10.1002/2013JD021371.

Waliser, D. E., and Coauthors, 2009: Cloud ice: A climate model challenge with signs and expectations of progress. J. Geophys. Res., 114, D00A21, https://doi.org/10.1029/2008JD010015.

Wing, A. A., and K. A. Emanuel, 2014: Physical mechanisms controlling self-aggregation of convection in idealized numerical modeling simulations. J. Adv. Model. Earth Syst., 6, 59-74, https://doi.org/10.1002/2013MS000269.

—, and T. W. Cronin, 2016: Self-aggregation of convection in long channel geometry. Quart. J. Roy. Meteor. Soc., 142, 1-15, https://doi.org/10.1002/qj.2628.

Wu, C.-C., S.-N. Wu, H.-H. Wei, and S. F. Abarca, 2015: The role of convective heating in tropical cyclone eyewall ring evolution. J. Atmos. Sci., 73, 319-330, https://doi.org/10.1175/JAS-D-150085.1.

Wu, S., and B. J. Soden, 2017: Signatures of tropical cyclone intensification in satellite measurements of ice and liquid water content. Mon. Wea. Rev., 145, 4081-4091, https://doi.org/ 10.1175/MWR-D-17-0046.1.

Yanai, M., S. Esbensen, and J. Chu, 1973: Determination of bulk properties of tropical cloud clusters from large-scale heat and moisture budgets. J. Atmos. Sci., 30, 611-627, https://doi.org/ 10.1175/1520-0469(1973)030<0611:DOBPOT >2.0.CO;2.

Zagrodnik, J. P., and H. Jiang, 2014: Rainfall, convection, and latent heating distributions in rapidly intensifying tropical cyclones. J. Atmos. Sci., 71, 2789-2809, https://doi.org/10.1175/ JAS-D-13-0314.1. 